\title{
Virtual Screening in Pharmacokinetics, Bioactivity, and Toxicity of the Amburana cearensis Secondary Metabolites
}

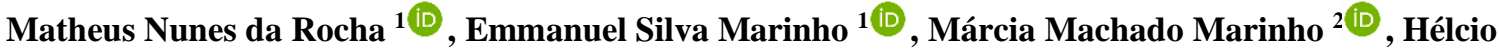 \\ Silva dos Santos ${ }^{3, * \text { (D) }}$
}

1 Group of Theoretical Chemistry and Electrochemistry, State University of Ceará, Limoeiro do Norte, CE, Brazil; nunes.rocha@aluno.uece.br (M.N.R.); emmanuel.marinho@uece.br (E.S.M);

2 Faculty of Education, Science and Letters of Iguatu, State University of Ceará, Iguatu, CE, Brazil; marcia.marinho@uece.br (M.M.M.);

Group of Theoretical Chemistry and Electrochemistry, State University of Ceará, Limoeiro do Norte, CE, Brazil; (E.S.M.);

3 Science and Technology Centre, Chemistry Course, State University Vale do Acaraú, Sobral, CE, Brazil; helciodossantos@gmail.com (H.S.S.);

* Correspondence: helciodossantos@gmail.com (H.S.S.);

Received: 26.10.2021; Revised: 30.11.2021; Accepted: 2.12.2021; Published: 12.12.2021

\begin{abstract}
Bioprospecting has contributed to the work of pharmaceutical chemists in the development and commercial disposal of new drugs. Currently, the pharmaceutical industry has emphasized drugs produced from bioactive compounds extracted from natural sources, based on popular medicine discussed in the literature, such as secondary metabolites isolated from the stem bark and seeds of the Amburana cearensis, rich in coumarin derivatives, flavonoids, and phenolic acids and is popularly used in the treatment of respiratory diseases and with anti-inflammatory and antioxidant bioactivity. This review is a study of the structure/activity and structure/property (SAR/SPA) relationship with the physicochemical properties calculated by the algorithms of the MarvinSketch software for the secondary metabolites of A. cearensis, as well as their correlation with in silico test values the SwissADME and admetSAR 2.0 servers and in vitro and in vivo models of the dataset from the PreADMET, GUSAR Online and PASS Online servers. The results showed that substances derived from coumarin, flavonoids, and phenolic acids have attributes of good permeability and low efflux, which favor their oral bioavailability, since phenolic heterosides, amburoside analogs, and biflavonoids are effective in local action as subcutaneous application, constituting promising antimicrobial, antiinflammatory and antioxidant therapeutic actions in their proper administration routes.
\end{abstract}

Keywords: Amburana cearensis; SAR study; amburosides; oral bioavailability; subcutaneous application.

(C) 2021 by the authors. This article is an open-access article distributed under the terms and conditions of the Creative Commons Attribution (CC BY) license (https://creativecommons.org/licenses/by/4.0/).

\section{Introduction}

Most commercially available drugs are based on a biomolecule with a promising pharmacological active principle, such as substances produced from compounds extracted from natural sources, whether for food or therapeutic purposes. The pharmaceutical industry has been emphasizing bioactive substances designed from natural sources due to their high feasibility and low production cost. However, many of these explored substances have their physicochemical and pharmacological properties not reported in the literature [1-4].

Medicinal plants are sources of molecules recognized by medicinal chemists and pharmacologists. Research that considers the bioactive potential of compounds derived from 
medicinal plants shows the support for physicians and pharmacologists in the characterization and development of new drugs from natural sources [5,6].

One of these natural sources is the arboreal plant of the genus A. cearensis (AC Smith Fabaceae), found in the Cerrado and Caatinga biome in northeastern Brazil and several countries in South America. Popularly known as "Cumaru" or "Imburana-de-cheiro", the plant is of inestimable importance from the therapeutic and commercial point of view. The bark of the stem of this species is widely used in folk medicine as an anti-inflammatory and syrup to fight respiratory diseases such as flu, colds, bronchitis, and asthma [7-9].

In previously published studies, secondary metabolites isolated from the stem bark of Amburana cearensis such as ayapin (1), phenolic acids protocatechuic (2) and vanillic (3), 6coumaryl-protocatechuate (4), phenolic heterosides amburoside A and B (5 and 6), the flavonoids 4'methoxy-fisetin (7), isokaempferide (8), kaempferol (9), quercetin (10) and afrormosin (11), $\beta$-sitosterol glucoside mixtures (12 and 13) and the biflavonoids amburanin $\mathrm{A}$ and B (14 and 15), as well as substances isolated from seeds rich in coumarins such as 6hydroxycoumarin (16), o-coumaric acid (17) and their analogs (Z)-o-coumaric acid glucoside (18) and (E)-o-coumaric acid (19) in addition to the esterified analog of amburoside (20) (Figure 2) obtained significant anti-inflammatory and antioxidant activities [10-14].

Thus, the objective of this work was to carry out an evaluation of their antiinflammatory and antioxidant activities with related enzymatic targets, as well as their pharmacokinetic properties of absorption, distribution, metabolism, excretion (ADME), toxicity, and structure-activity relationships (SAR) through computer-aided drug design (CADD) techniques.

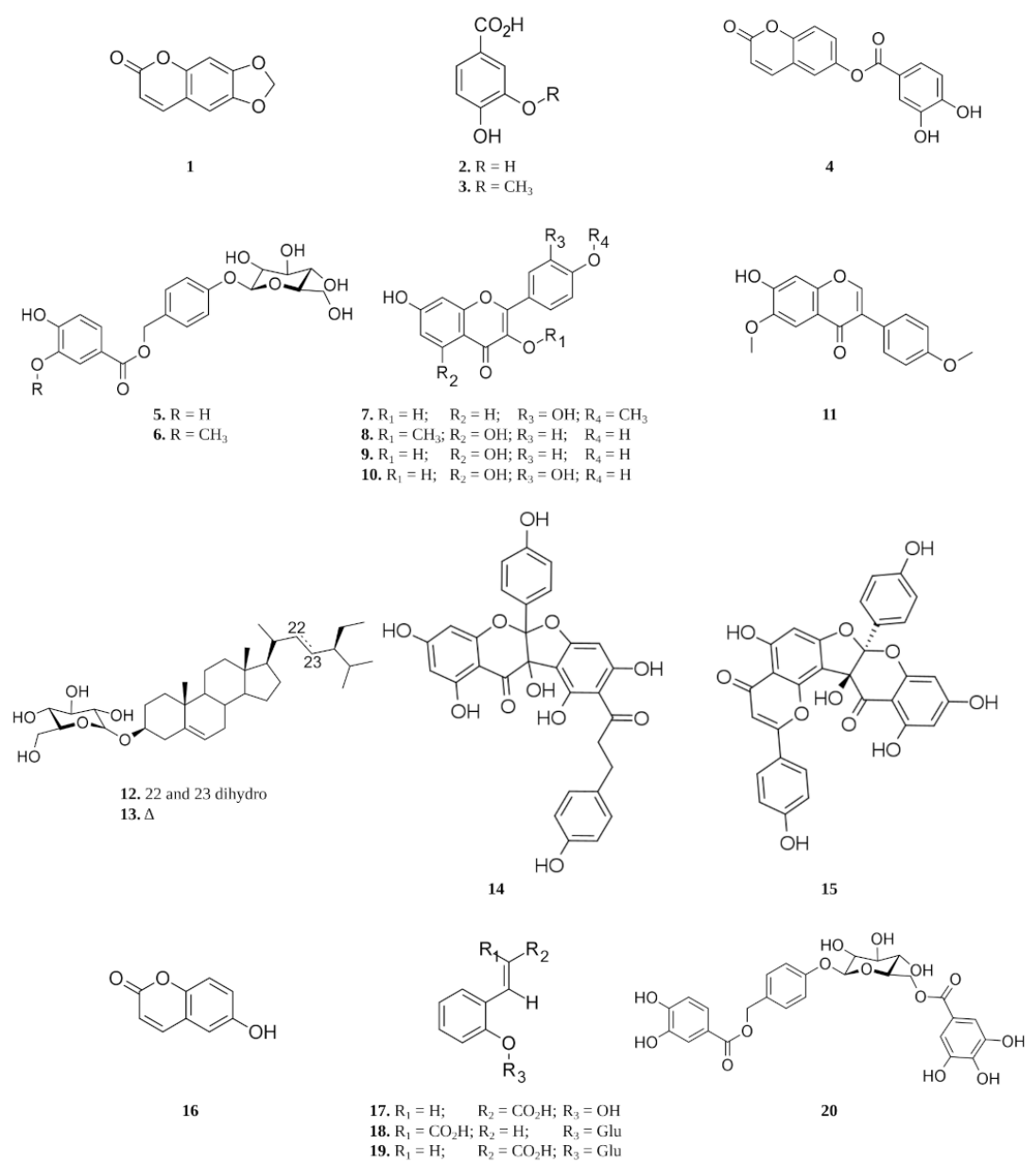

Figure 2. Structure of secondary metabolites isolated from the stem bark and seeds from Amburana cearensis. 


\section{Materials and Methods}

Figure 3 shows the flowchart used in this study, where molecules were designed and treated according to their dominant microspecies at $\mathrm{pH} 7.4$ for molecular docking simulations. Then, the substances from A. cearensis were submitted to an in silico screening of physicochemical and medicinal chemistry properties through the drug discovery tools of the CADD approaches, where the drug-likeness characteristics and toxicity profiles were evaluated for the promotion of substances such as medicines in their proper administration routes. The methodology implemented in recent years to optimize the initial stages of characterizing bioactive substances as potential medicines [16-21].

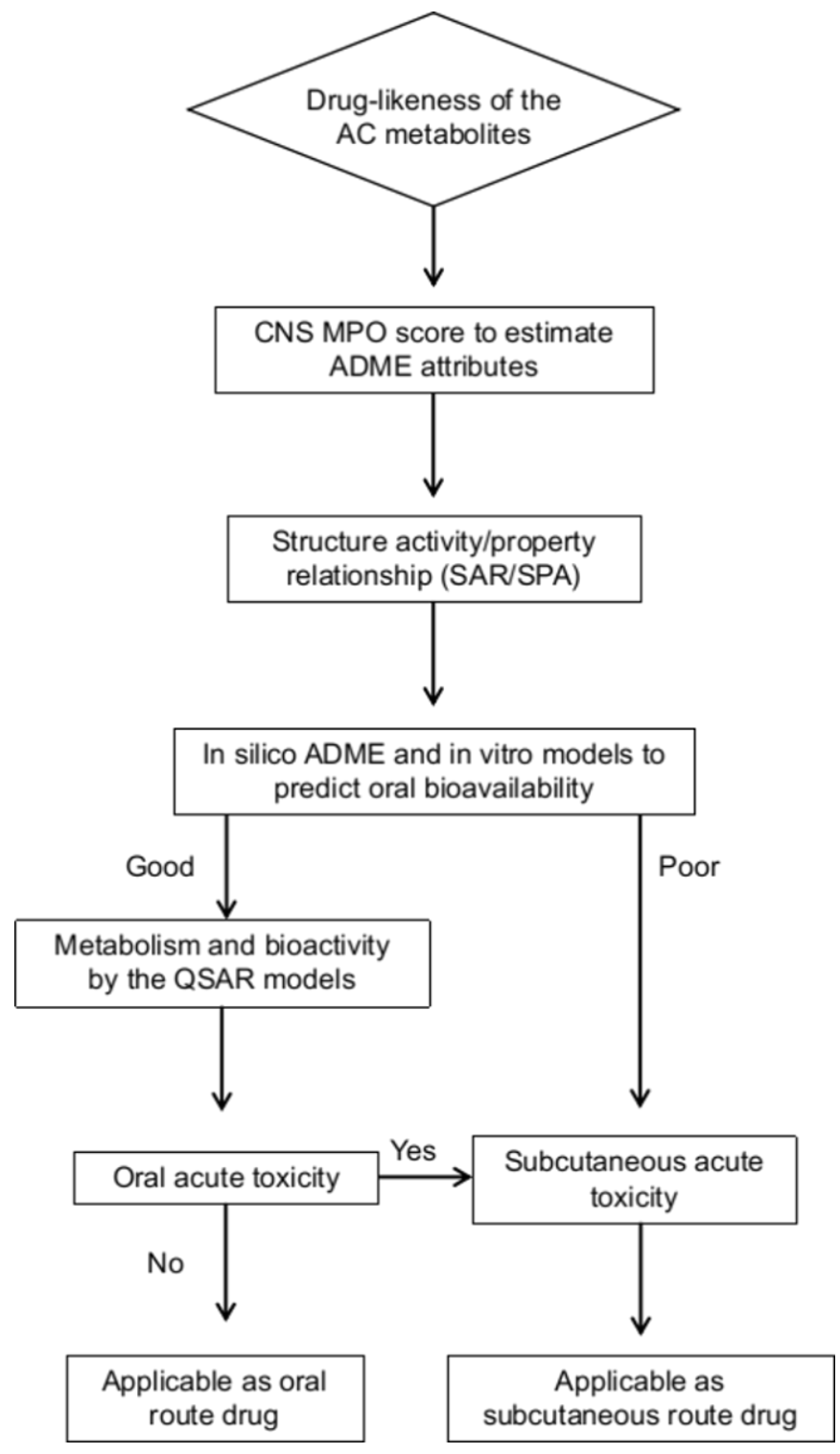

Figure 3. Flowchart illustrating the procedure for promoting substances extracted from Amburana cearensis as medicine using CADD tools.

2.1. Drug-likeness, estimation of ADME attributes, and structure/activity relationships (SAR).

The molecules (1-20) were designed to calculate the physicochemical properties of the ionization constant $(\mathrm{pKa})$, partition coefficients $(\log \mathrm{P})$, distribution $(\log \mathrm{D})$, and solubility $(\log S)$, as well as the extensive properties of molecular weight (MW), acceptors and H-bond donors (HBA and HBD), the number of rotatable bonds (Nrot) and topological polar surface 
area (TPSA) [22] in JS MarvinSketch version 21.3 software, ChemAxon (https://chemaxon.com/products/marvin) and then applied to the drug-likeness filters of the "rule of five" (RO5) of Lipinski (2004) [23] and to the rule of Veber et al., (2002) [24] and the oral bioavailability criteria by the method of Martin (2005) [25].

Furthermore, the physicochemical properties were applied to CNS MPO desirability score filters to identify compounds with desirable drug-likeness, ADME (absorption, distribution, metabolism, and excretion), and safety properties [26], as well as structure relationship properties and activity/property (SAR/SPA). The $\log$ P, $\log \mathrm{D}, \mathrm{MW}$, and TPSA values were used to graphically predict intestinal permeability and absorption according to the reference [27]. The TPSA was used to calculate the percentage of absorption (\% Abs) according to equation: $\% \mathrm{Abs}=109-0.345 \mathrm{x}$ TPSA [28].

\subsection{In silico prediction of pharmacokinetic properties.}

The properties of permeability and oral bioavailability, fundamental attributes of ADME, were predicted by the in silico method of Brain Or Intestinal EstimateD permeation (BOILED-Egg) from the SwissADME platform (http://swissadme.ch/index.php) [29,30], through the molecular descriptors of WlogP and TPSA. At the same time, the apparent permeability coefficients (Papp in $\times 10^{-6} \mathrm{~cm} / \mathrm{s}$ ) and free molecular fraction in the systemic circulation were predicted by the in vitro methods of permeability in a Madin-Darby Canine Kidney (MDCK) model and binding to plasma proteins (PPB), respectively, from the PreADMET server (https://preadmet.bmdrc.kr/adme/).

\subsection{Metabolism, biological activity, and antitargets by the QSAR screening.}

First-pass metabolism of Amburana cearensis phytochemicals was predicted by screening the applicability domain of the admetSAR 2.0 webserver (http://lmmd.ecust.edu.cn/admetsar2/) [31] for substrate and cytochrome P450 (CYP450) isoenzyme inhibitor 1A2, 2C19, 2C9, 2D6, and 3A4, as well as phase II metabolism by UDPglucuronosyltransferase (UGT) enzyme catalyzes [32] and excretion by organic cation transporter (OCT2) inhibition.

Furthermore, the substances were submitted to statistical screening on the PASS Online web server (http://way2drug.com/PassOnline/predict.php) [33] for inhibition of kinase, oxidoreductase and 3CLpro (coronavirus) and antiprotozoal (Leishmania), antiviral (Influenza), anti-inflammatory and antioxidant bioactivity, as well as the estimation of the inhibition coefficient $\left(-\log _{10} K_{\mathrm{i}}\right)$ for the various biological targets of the receptor, enzyme and transporter classes by the QSAR applicability domain of the GUSAR antitargets tool (http://way2drug.com/Gusar/antitargets.html) [34].

\subsection{Acute rodent toxicity and toxicological effects prediction.}

Acute toxicity was predicted by the QSAR applicability domain for lethal dose ( $\left.\mathrm{LD}_{50}\right)$ in rats by oral and subcutaneous (SC) administration of the GUSAR Acute Rat Toxicity web server dataset (http://way2drug.com/Gusar/acutoxpredict.html) [35]. Toxic effects were predicted by the probability of intestinal, hepatic, carcinogenic, mutagenic, cytotoxic, and vascular toxic activity $(\mathrm{Pa})$ from the toxicity models of the PASS Online web server (http://way2drug.com/PassOnline/predict.php) [33]. 


\section{Results and Discussion}

\subsection{Drug-likeness properties.}

High oral bioavailability is a medicinal property of considerable importance for projecting a new bioactive compound as a therapeutic agent $[36,37]$. The in vivo properties of a substance can be strongly influenced by its physicochemical properties. To facilitate the process of discovering new drugs, the famous "rule of 5" (RO5), or "rule of Pfizer", by Lipinski (2004) [23] is based on four physicochemical parameters where it exists the probability of a compound is an oral drug: $\mathrm{MW} \leq 500, \log \mathrm{P} \leq 5, \mathrm{HBA} \leq 10$ (count of $\mathrm{N}$ or $\mathrm{O}$ atoms) and $\mathrm{HBD}$ $\leq 5$ (count of NH or OH groups). Two other parameters identified by Veber et al. (2002) [24] of several swivel links (Nrot $\leq 10)$ and polarity (TPSA $\left.\leq 140 \AA^{2}\right)$ are associated with a good oral bioavailability observed in rats as a predictive model of human oral bioavailability. For good oral bioavailability, a compound must be relatively small, uncharged, and essentially lipophilic [38-40].

Thus, it is possible to observe that the analogs sitogluside (12) and stigmasterol glucoside (13) have a double violation of the type MW > $500 \mathrm{~g} / \mathrm{mol}$ and $\log \mathrm{P}>5$, being larger and more lipophilic compounds than the ideal predicted by RO5, while the esterified analog of amburoside (20) has a triple violation of type MW > 500, HBA > 10 and HBD > 5 and the biflavonoids amburanin A and B (14 and 15) violated all four criteria of RO5, resulting in a higher polarity to that provided for by Veber's rule (TPSA > $140 \AA^{2}$ ), limiting their respective bioavailability by oral administration, as well as the interaction of these compounds with therapeutic biological targets (Table 1) [41].

The parameters observed by Martin (2005) [25] can refine a series of compounds regarding their oral bioavailability: a) the bioavailable fraction (F) of anions drops by $85 \%$ if the TPSA $\leq 75 \AA^{2}$; b) for $56 \%$ if $75<$ TPSA $\leq 150 \AA^{2}$; c) to $11 \%$ if TPSA $>150 \AA^{2}$; d) the F for cations and neutrals drops by $55 \%$ when not in violation of RO5; c) to $17 \%$ in compounds violating RO5.

Thus, pKa values between 3.0-4.16 of the compounds vanillic acid (2) and o-coumaric acid (17) suggest that they are strong acids with high oral bioavailability since their TPSA values $<75 \AA^{2}$ show an F score in the order of 0.85 . Furthermore, pKa values for the flavonoids 4'-methoxy-fisetin (7), isokaempferide (8), kaempferol (9), quercetin (10), and afrormosin (11) between 6.3-6.9 indicate that they are weak acids where a bioavailability ranges from 0.56$0.85 F$, with afrormosin (11) higher $F$ score due to its low polarity. In addition, the violators above the RO5 rule have an $F$ score of 0.17 , except for the biflavonoid amburanin B (15), loaded at physiological $\mathrm{pH}$ and highly polar, with an $F$ score of 0.11 (Table 1 ).

Table 1. Drug-likeness parameters of phytochemical from A. cearensis.

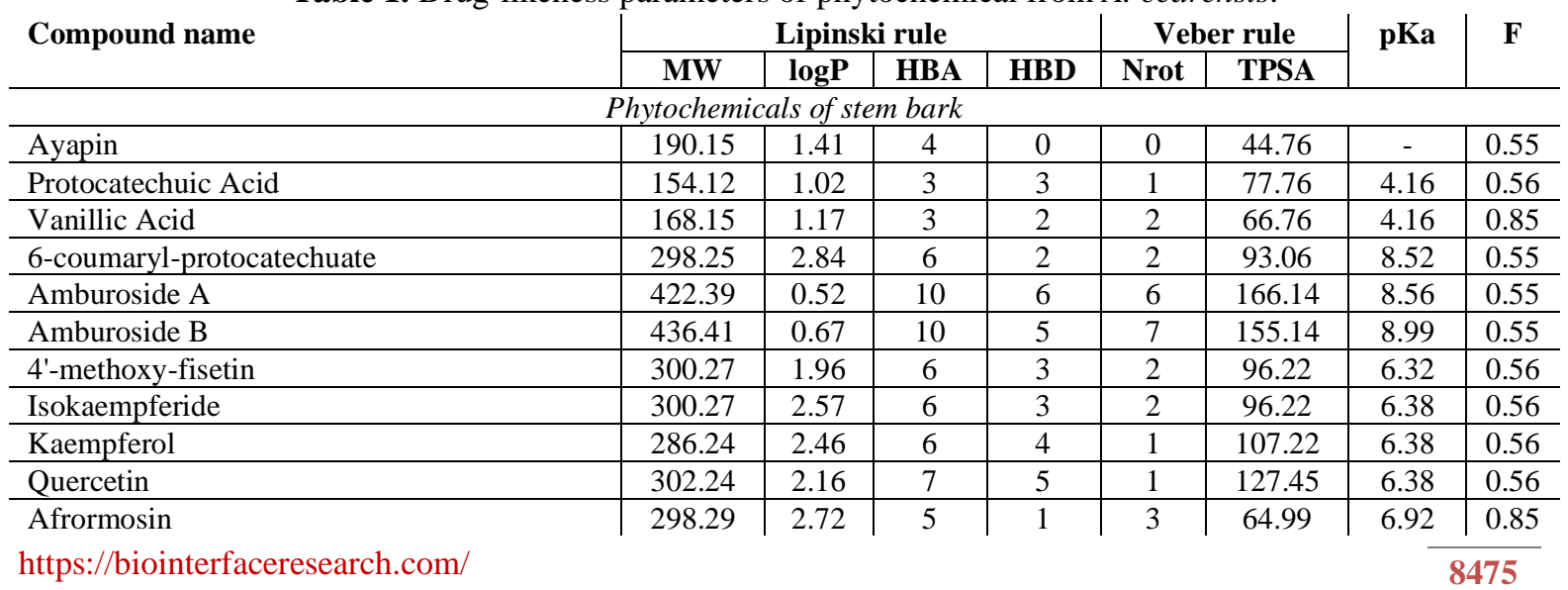




\begin{tabular}{|c|c|c|c|c|c|c|c|c|}
\hline \multirow[t]{2}{*}{ Compound name } & \multicolumn{4}{|c|}{ Lipinski rule } & \multicolumn{2}{|c|}{ Veber rule } & \multirow[t]{2}{*}{ pKa } & \multirow[t]{2}{*}{$\mathbf{F}$} \\
\hline & MW & $\log P$ & HBA & HBD & Nrot & TPSA & & \\
\hline Sitogluside & 576.86 & 6.07 & 6 & 4 & 9 & 99.38 & 12.21 & 0.17 \\
\hline Stigmasterol Glucoside & 574.84 & 5.71 & 6 & 4 & 8 & 99.38 & 12.21 & 0.17 \\
\hline Amburanin A & 558.50 & 6.32 & 11 & 7 & 5 & 194.21 & 7.64 & 0.17 \\
\hline Amburanin B & 554.46 & 5.13 & 11 & 6 & 2 & 183.21 & 7.09 & 0.11 \\
\hline \multicolumn{9}{|c|}{ Phytochemicals of seeds } \\
\hline 6-hydroxy-coumarin & 162.14 & 1.48 & 3 & 1 & 0 & 46.53 & 9.41 & 0.55 \\
\hline$o$-coumaric acid & 164.16 & 1.83 & 2 & 2 & 2 & 57.53 & 3.85 & 0.85 \\
\hline (Z)-o-coumaric acid glucoside & 326.30 & -0.44 & 7 & 5 & 5 & 136.68 & 3.01 & 0.56 \\
\hline (E)-o-coumaric acid glucoside & 326.30 & -0.44 & 7 & 5 & 5 & 136.68 & 3.51 & 0.56 \\
\hline Amburoside analog & 574.49 & 2.11 & 14 & 8 & 8 & 232.90 & 7.98 & 0.17 \\
\hline Drug- lead-like properties & $\leq 500$ & $\leq 5$ & $\leq 10$ & $\leq 5$ & $\leq 10$ & $\leq 140$ & & \\
\hline
\end{tabular}

Note: MW (Molecular Weight in g/mol); HBA (H-Bond Acceptors); HBD (H-Bond Donors); Nrot (Number of rotatable bonds); TPSA (Topological Polar Surface Area in $\AA^{2}$ ); F (bioavailability score).

\subsection{CNS MPO desirability as a measure of ADME and drug-likeness.}

The discovery of drugs with activity in the central nervous system (CNS) presents specific challenges, as they constitute chemical entities that must have favorable pharmacokinetics and that have safe properties to penetrate the blood-brain barrier (BBB) [42]. A new CNS drug optimization technique (CNS MPO desirability score) was developed to improve the planning of drugs with activity in the brain, since they have the ideal drug-like properties, based on six fundamental physicochemical parameters: a) $\log \mathrm{P} \leq 3$; b) $\log \mathrm{D} \leq 2$; c) $\mathrm{MW} \leq 360 \mathrm{~g} / \mathrm{mol}$; d) $40<$ TPSA in $\AA^{2} \leq 90$; e) $\mathrm{HBD} \leq 0.5$; pKa score $\leq 8$. Thus, the individual transformed value (T0) below the limit is $\mathrm{T} 0=1.0$, while values above the limits have T0 tending to 0.00, where the CNS MPO score is the sum of individual contributions, which may vary from 0 to 6 . Compounds with a CNS MPO score $\geq 4$ have the best drug-likeness properties [26].

In this study, the algorithm was applied to the phytochemicals isolated from $A$. cearensis (1-20) (Figure 2) from the chemical and pharmacological review made by Almeida et al. (2010) [12]. With the results in Table 2, it was possible to observe that amburosides A and B (5 and 6), sitogluside (12), stigmasterol glucoside (13), the biflavonoids amburanin A and B (14 and 15) and the esterified analog of amburoside (20) obtained a CNS MPO score < 4 , because they are molecules with the highest mass values, while a large number of hydrogen bond donors (HBD) substantially increase their polarities (Figure 4), evaluated in TPSA > 90 $\AA^{2}$. In addition, the remaining 13 compounds had a CNS MPO score $\geq 4$. These scores suggest that these compounds allow projecting an ideal spectrum for use as an oral drug, maintaining most of the desirable attributes of ADME, including CNS activity (Table 2).

The ideal in vitro ADME characteristics of a compound increase as its CNS MPO score approaches 6. In this way, it is possible to highlight the substance ayapin (1), the phenolic acids protocatechuic (2) and vanillic (3), the flavonoids 4'-methoxy-fisetin (7), isokaempferide (8), and aformosin (11), as well as the coumarin analogs, 6-hydroxy-coumarin (16) and o-coumaric acid (17). Thus, they represent a spectrum of drugs with a good alignment of the three ADME attributes: high passive permeability (Papp), low passive efflux of P-gp, and low metabolic clearance (CLint,u), as well as safety requirements such as high viability cellular (THLE Cv) and low potential blocking hERG transport channels (human Ether-a-go-go Related Gene) [26] constituting potential pharmacological agents with greater desirability of ADME and safety attributes to penetrate the BBB (Table 2). 
3.3. Structure-activity/property relationship of phytochemicals From A. cearensis.

Most of the time, improving pharmacological activity, solubility, and permeability properties is more advantageous during the drug candidate planning process. In this way, medicinal chemists have developed techniques to determine the relationship between structure and activity/property (SAR/SPA) in a qualitative approach $[43,44]$.

A very important factor in developing new drugs is lipophilicity $(\log \mathrm{P})$. This is a structural property that describes solubility properties, ADME, and pharmacological activity. As a general rule, good oral bioavailability is associated with values of $0<\log \mathrm{P}<3$ (good permeability and solubility) since very high values of $\log P$ result in low aqueous solubility, while very low values make it difficult to penetrate the lipid bilayer of cell membranes [23,26]. At the same time that compounds in the MW range $<450 \mathrm{~g} / \mathrm{mol}$ are small enough to be well absorbed by the administration, in addition to readily penetrating the BBB [24,39].
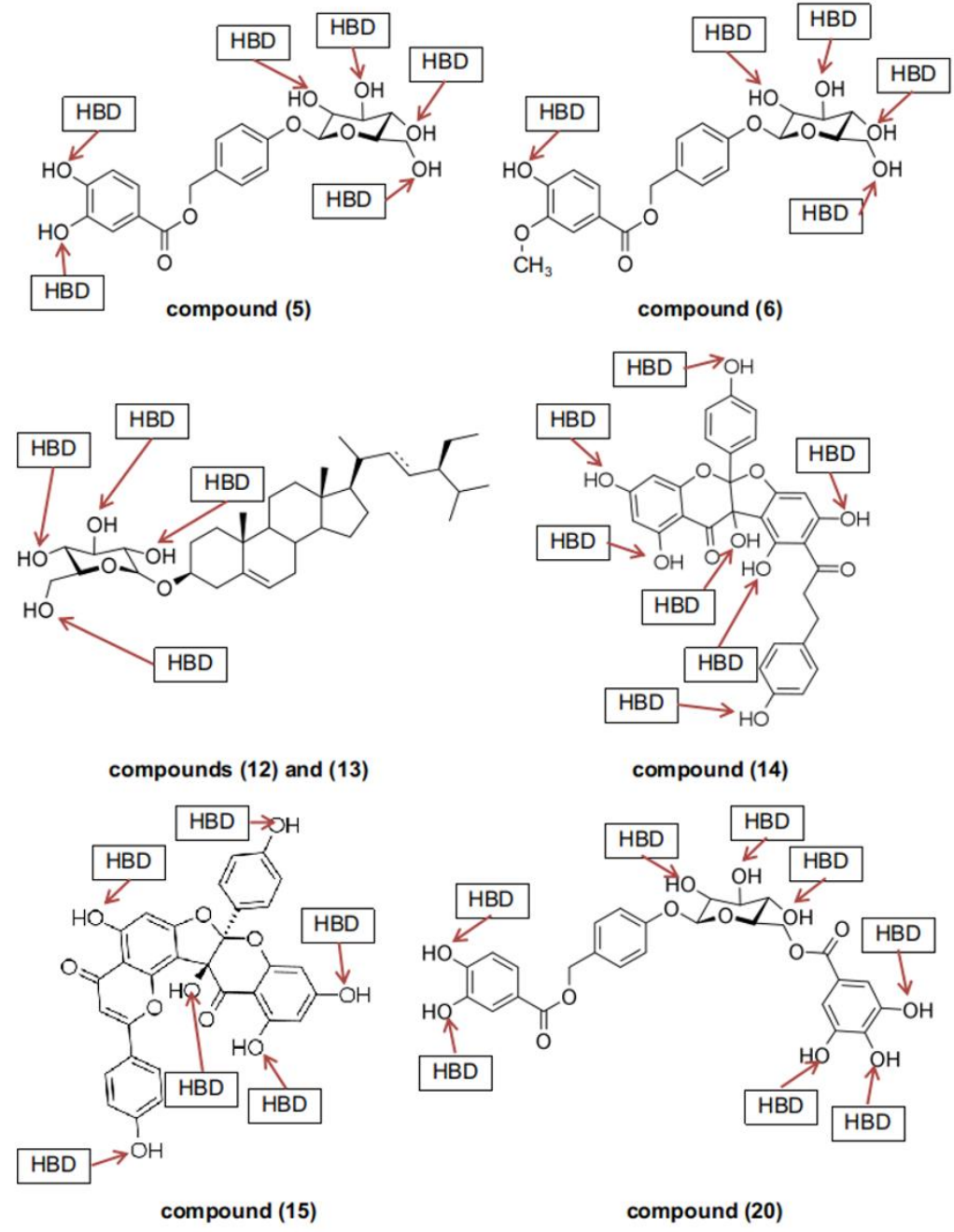

Figure 4. Hydrogen bond donors (HBD) of compounds with CNS MPO score $<4$.

Figure 5 shows the structural contributions to the lipophilicity of phytochemicals isolated from A. cearensis, where it is possible to observe that the compounds ayapin (1), 6coumaryl-protocatechuate (4), the flavonoids 4'-methoxy-fisetin (7), isokaempferide (8), kaempferol (9), quercetin (10) and afrormosin (11), and 6-hydroxy-coumarin (16) are the small compounds that are in the ideal range of lipophilicity and therefore possess the properties ideals of solubility and permeability that facilitate absorption by oral administration. This is verifiable in the golden triangle model [45], where the combined values of MW and lipophilicity in a 
physiological medium measured by the distribution coefficient $(\log \mathrm{D}$ 7.4) leave these substances in the center of the predicted spectrum for good oral absorption (Figure 6A).

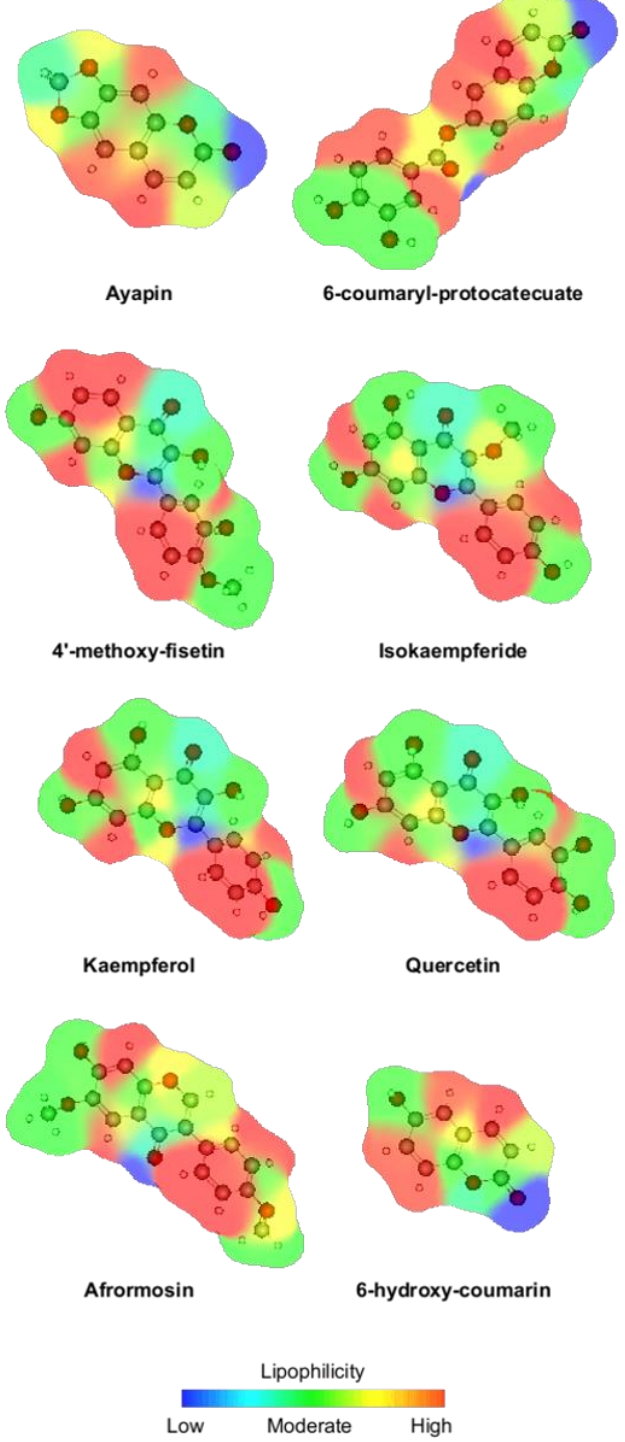

Figure 5. Lipophilicity $(\log \mathrm{P})$ structural contributions of the best permeable compounds of A. cearensis.

The statistical predictive model of Egan et al. (2000) [46] uses a graph formed between the structural descriptors of $\log \mathrm{P}$ and TPSA to elucidate well-absorbed compounds by oral administration of poorly absorbed compounds, in addition, to relate these parameters to violations of the "rule of five" (RO5) of Lipinski (2004) [23]. Thus, compounds within the ellipse formed by the limits $\log \mathrm{P} \leq 5.88$ and TPSA $\leq 131.6 \AA^{2}$ have structural properties that favor their oral use with a high absorption percentage.

With the calculated values in table 2 and the graph plot in Figure 6A, it is possible to observe the amburoside analogs A and B (5 and 6) are outside the polarity limit, with a total of 10 oxygenated groups and with a strong contribution from their glucoside groups. Although the substances sitogluside (12) and stigmasterol glucoside (13) has a highly water-soluble glucoside group, their polycyclic chains ensure high lipophilicity $(\log \mathrm{P}>5)$, decreasing their absorption viability. The large size and large number of oxygenated groups (HBA > 10) of the biflavonoids amburanin A and B (14 and 15) and the esterified analog of amburoside (20) results in a high polarity (TPSA > $180 \AA^{2}$ ), leaving these substances far from the ideal absorption spectrum. Furthermore, it is possible to observe the substances quercetin (10) and 
o-coumaric acid glucoside isomers (18 and 19) in the vicinity of the ellipse, as they are small compounds with a high number of oxygenated groups $(\mathrm{HBA}=7)$, which results in low lipophilicity and high polarity to be absorbed in the intestine. Thus, their calculated absorptions (\% Abs) resulted in values below $75 \%$, therefore impracticable for administration due to their low intestinal absorption, resulting in low bioavailability.

On the other hand, the other substances are within the expected spectrum of lipophilicity and polarity for good absorption (Figure 6B), where it is possible to highlight the compounds ayapin (1), the phenolic acids protocatechuic (2), and vanillic (3), the flavonoid afrormosin (11), and the coumarin derivatives, 6-hydroxy-coumarin (16) and o-coumaric acid (17) as the best-absorbed compounds (\%Abs > 80) and therefore have the best-predicted bioavailability (Table 2).
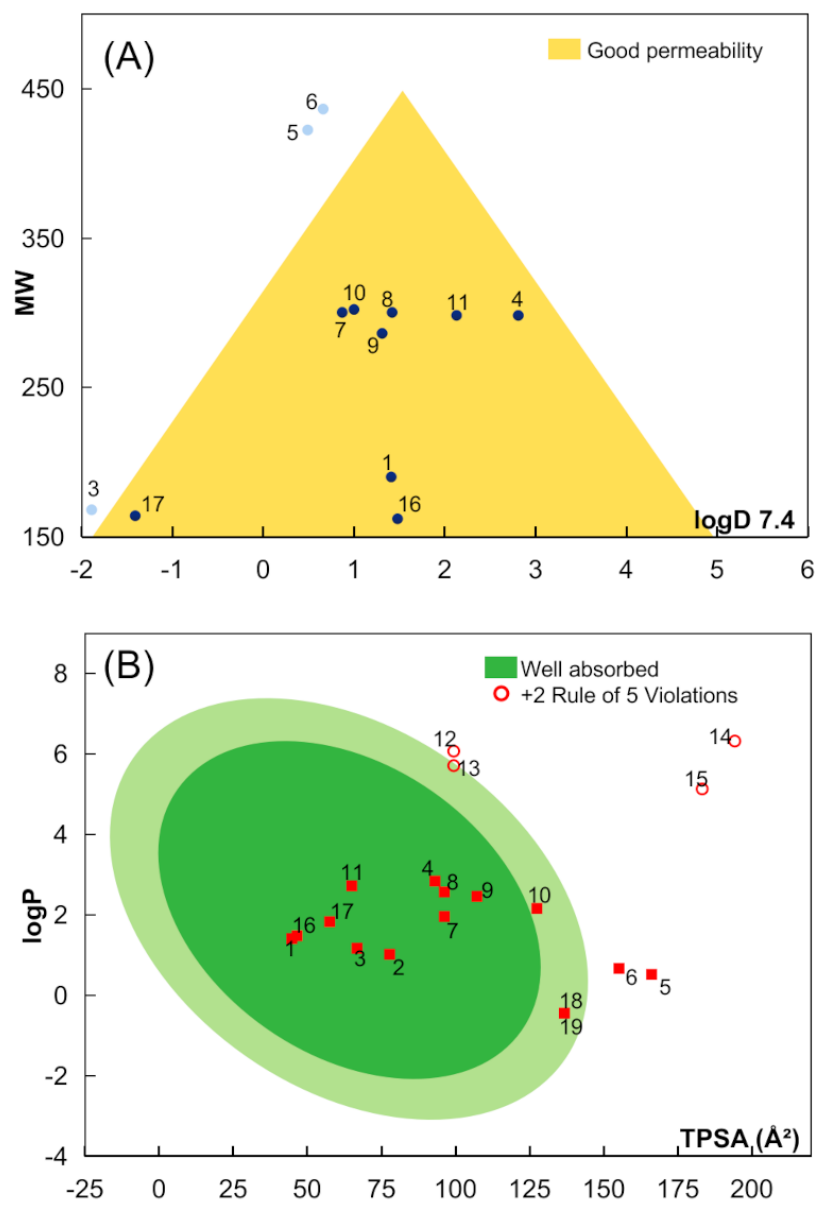

Figure 6. (A) Golden triangle model and (B) Egan-egg model to predict permeability and oral absorption of phytochemicals from $A$. cearensis.

Table 2. CNS MPO Scores and Individual Transformed Scores (T0) calculated percentage of absorption of phytochemicals from A. cearensis.

\begin{tabular}{|c|c|c|c|c|c|c|c|c|}
\hline Compound name & $\begin{array}{c}\log P \\
\text { T0 }\end{array}$ & $\begin{array}{c}\log D \\
\text { T0 }\end{array}$ & $\begin{array}{c}\text { MW } \\
\text { T0 }\end{array}$ & TPSA T0 & $\begin{array}{c}\text { HBD } \\
\text { T0 }\end{array}$ & $\begin{array}{c}\text { pKa } \\
\text { T0 }\end{array}$ & $\begin{array}{c}\text { CNS } \\
\text { MPO }\end{array}$ & $\%$ ABS \\
\hline \multicolumn{9}{|c|}{ Phytochemicals of seeds } \\
\hline Ayapin & 1.00 & 1.00 & 1.00 & 1.00 & 1.00 & 1.00 & 6.00 & 93.56 \\
\hline Protocatechuic Acid & 1.00 & 1.00 & 1.00 & 1.00 & 0.25 & 1.00 & 5.25 & 82.17 \\
\hline Vanillic Acid & 1.00 & 1.00 & 1.00 & 1.00 & 0.50 & 1.00 & 5.50 & 85.97 \\
\hline 6-coumaryl-protocatechuate & 1.00 & 0.60 & 1.00 & 0.90 & 0.50 & 1.00 & 4.99 & 76.89 \\
\hline Amburoside A & 1.00 & 1.00 & 0.55 & 0.00 & 0.00 & 1.00 & 3.55 & 51.68 \\
\hline Amburoside B & 1.00 & 1.00 & 0.45 & 0.00 & 0.00 & 1.00 & 3.45 & 55.48 \\
\hline 4'-methoxy-fisetin & 1.00 & 1.00 & 1.00 & 0.79 & 0.25 & 1.00 & 5.04 & 75.80 \\
\hline Isokaempferide & 1.00 & 1.00 & 1.00 & 0.79 & 0.25 & 1.00 & 5.04 & 75.80 \\
\hline \multicolumn{9}{|c|}{ https://biointerfaceresearch.com/ $\quad 8479$} \\
\hline
\end{tabular}




\begin{tabular}{|c|c|c|c|c|c|c|c|c|}
\hline Compound name & $\begin{array}{c}\log P \\
\text { T0 }\end{array}$ & $\begin{array}{c}\log D \\
\text { T0 }\end{array}$ & $\begin{array}{c}\text { MW } \\
\text { T0 }\end{array}$ & TPSA T0 & $\begin{array}{c}\text { HBD } \\
\text { T0 }\end{array}$ & $\begin{array}{c}\text { pKa } \\
\text { T0 }\end{array}$ & $\begin{array}{l}\text { CNS } \\
\text { MPO }\end{array}$ & $\% \mathrm{ABS}$ \\
\hline Kaempferol & 1.00 & 1.00 & 1.00 & 0.43 & 0.00 & 1.00 & 4.43 & 72.01 \\
\hline Quercetin & 1.00 & 1.00 & 1.00 & 0.00 & 0.00 & 1.00 & 4.00 & 65.03 \\
\hline Afrormosin & 1.00 & 0.94 & 1.00 & 1.00 & 0.75 & 1.00 & 5.69 & 86.58 \\
\hline Sitogluside & 0.00 & 0.00 & 0.00 & 0.69 & 0.00 & 1.00 & 1.69 & 74.71 \\
\hline Stigmasterol Glucoside & 0.00 & 0.00 & 0.00 & 0.69 & 0.00 & 1.00 & 1.69 & 74.71 \\
\hline Amburanin A & 0.00 & 0.00 & 0.00 & 0.00 & 0.00 & 1.00 & 1.00 & 42.00 \\
\hline Amburanin B & 0.00 & 0.00 & 0.00 & 0.00 & 0.00 & 1.00 & 1.00 & 45.79 \\
\hline \multicolumn{9}{|c|}{ Phytochemicals of seeds } \\
\hline 6-hydroxy-coumarin & 1.00 & 1.00 & 1.00 & 1.00 & 0.75 & 1.00 & 5.75 & 92.95 \\
\hline$o$-coumaric acid & 1.00 & 1.00 & 1.00 & 1.00 & 0.50 & 1.00 & 5.50 & 89.15 \\
\hline (Z)-o-coumaric acid glucoside & 1.00 & 1.00 & 1.00 & 0.00 & 0.00 & 1.00 & 4.00 & 61.84 \\
\hline (E)-o-coumaric acid glucoside & 1.00 & 1.00 & 1.00 & 0.00 & 0.00 & 1.00 & 4.00 & 61.84 \\
\hline Amburoside analog & 1.00 & 1.00 & 0.00 & 0.00 & 0.00 & 1.00 & 3.00 & 28.65 \\
\hline
\end{tabular}

\subsection{In silico pharmacokinetic properties as a validation of the SAR analysis.}

The Brain or Intestinal Estimated permeation (BOILED-Egg) in silico method, from the SwissADME platform, consists of an instantaneous tracking of compounds passively permeable to the gastrointestinal tract (GI) and the blood-brain barrier (BBB) through traced lipophilicity profiles (WlogP) [47] and polarity (TPSA) [22]. The server also uses a support vector machine algorithm and a dataset for substrates and non-substrates of P-glycoprotein (Pgp) [30]. Together with the numerical data of the apparent permeability coefficients (Papp) of the in vitro models MDCK [48] and plasma protein binding (PPB) in $\mathrm{pH} 7.4$ of the PreADMET platform, it constitutes a predictive method that correlates physicochemical properties and in vitro datasets to estimate the pharmacokinetics and oral bioavailability attributes of $\mathrm{A}$. cearensis phytochemicals.

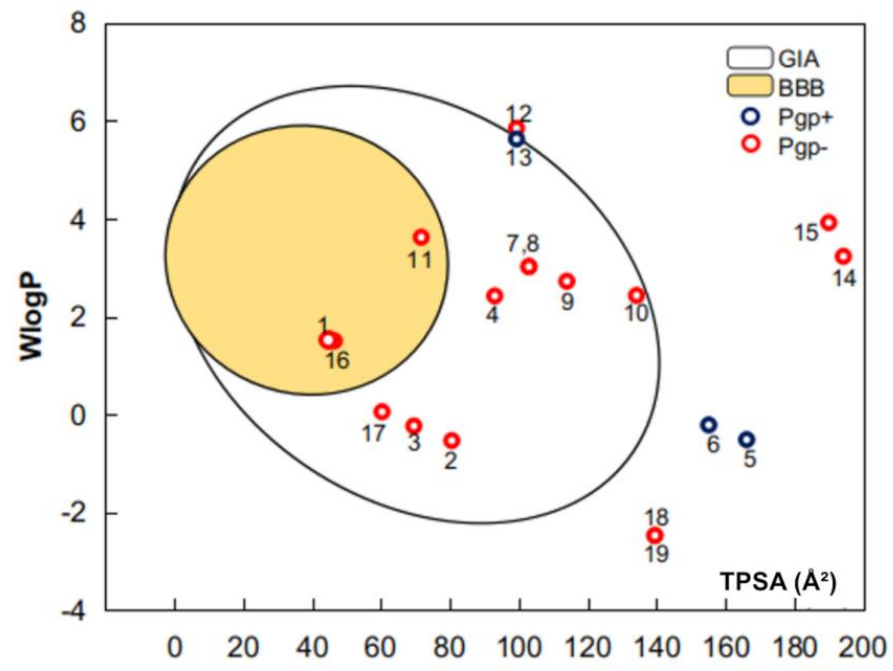

Figure 7. BOILED-Egg with estimates of gastrointestinal (GI) and blood-brain barrier (BBB) permeability of phytochemicals from A. cearensis.

The systematic analysis between the two platforms shows that Papp values $>1.0 \times 10^{-6}$ $\mathrm{cm} / \mathrm{s}$ associated with ayapin (1), the flavonoids 4'-methoxy-fisetin (7) and afrormosin (11), and derivatives of coumarin 6-hydroxy-coumarin (16) and o-coumaric acid (17) suggest that they are substances with high gastrointestinal permeability and capable of penetrating the BBB [26], since ayapin (1), afrormosin (11) and 6-hydroxy-coumarin (16) are within the spectrum formed by the limits of $0.4<\mathrm{W} \log \mathrm{P}<6.0$ and TPSA $<79 \AA^{2}$, which give them the condition of high passive permeability by the BBB (Figure 7). It is worth noting that, although the substance stigmasterol glucoside (13) is within the predicted spectrum for a high passive intestinal 
permeability $\left(-2.3<\mathrm{W} \log \mathrm{P}<6.8\right.$ and TPSA $\left.<142 \AA^{2}\right)$, the molecule efflux back into the lumen of the gastrointestinal tract, for being a substrate of P-gp, in addition to binding $100 \%$ with plasma proteins, reflecting the decrease in its oral bioavailability (Table 3).

In addition, it is worth noting that the phenolic acids protocatechuic (2) and vanillic (3), the 6-coumaryl-protocatechuate (4), and the flavonoids isokaempferide (8), kaempferol (9), and quercetin (10) are substances with high passive gastrointestinal permeability and no central nervous system (CNS) activity, as their Papp $<1.0 \times 10^{-6} \mathrm{~cm} / \mathrm{s}$ indicate that they are unable to penetrate the BBB (Table 3).

Table 3. Pharmacokinetic information in $\mathrm{pH} 7.4$ of $A$. cearensis phytochemicals by in silico test and in vitro

\begin{tabular}{|c|c|c|c|c|c|c|c|}
\hline \multirow[b]{2}{*}{ Compound name } & \multicolumn{2}{|c|}{ models. } & \multirow[b]{2}{*}{ GI } & \multirow[b]{2}{*}{ Pgps } & \multirow[b]{2}{*}{ BBB } & \multirow[b]{2}{*}{$\begin{array}{c}\text { Papp } \\
(\text { MDCK) }\end{array}$} & \multirow[b]{2}{*}{$\%$ РPB } \\
\hline & $W \log P$ & TPSA & & & & & \\
\hline \multicolumn{8}{|c|}{ Phytochemicals of seeds } \\
\hline Ayapin & 1.52 & 44.76 & High & No & Yes & $5.00 \times 10^{-6}$ & 45.80 \\
\hline Protocatechuic Acid & -0.54 & 80.59 & High & No & No & $4.67 \times 10^{-7}$ & 16.75 \\
\hline Vanillic Acid & -0.24 & 69.59 & High & No & No & $5.63 \times 10^{-7}$ & 37.53 \\
\hline 6-coumaryl-protocatechuate & 2.42 & 93.06 & High & No & No & $9.50 \times 10^{-8}$ & 96.06 \\
\hline Amburoside A & -0.52 & 166.14 & Low & Yes & No & $9.16 \times 10^{-8}$ & 67.98 \\
\hline Amburoside B & -0.22 & 155.14 & Low & Yes & No & $7.88 \times 10^{-8}$ & 65.16 \\
\hline 4'-methoxy-fisetin & 3.02 & 102.96 & High & No & No & $2.11 \times 10^{-6}$ & 71.04 \\
\hline Isokaempferide & 3.02 & 102.96 & High & No & No & $6.15 \times 10^{-7}$ & 71.80 \\
\hline Kaempferol & 2.72 & 113.96 & High & No & No & $6.04 \times 10^{-7}$ & 76.48 \\
\hline Quercetin & 2.43 & 134.19 & High & No & No & $2.44 \times 10^{-7}$ & 78.06 \\
\hline Afrormosin & 3.62 & 71.73 & High & No & Yes & $1.44 \times 10^{-6}$ & 77.43 \\
\hline Sitogluside & 5.85 & 99.38 & Low & No & No & $1.22 \times 10^{-8}$ & 100 \\
\hline Stigmasterol Glucoside & 5.63 & 99.38 & High & Yes & No & $8.42 \times 10^{-9}$ & 100 \\
\hline Amburanin A & 3.23 & 194.21 & Low & No & No & $5.29 \times 10^{-9}$ & 100 \\
\hline Amburanin B & 3.92 & 189.95 & Low & No & No & $8.32 \times 10^{-6}$ & 100 \\
\hline \multicolumn{8}{|c|}{ Phytochemicals of seeds } \\
\hline 6-hydroxy-coumarin & 1.50 & 46.53 & High & No & Yes & $5.59 \times 10^{-6}$ & 11.01 \\
\hline$o$-coumaric acid & 0.05 & 60.36 & High & No & No & $2,14 \times 10^{-6}$ & 47.98 \\
\hline (Z)-o-coumaric acid glucoside & -2.48 & 139.51 & Low & No & No & $5.92 \times 10^{-8}$ & 41.25 \\
\hline (E)-o-coumaric acid glucoside & -2.48 & 139.51 & Low & No & No & $5.92 \times 10^{-8}$ & 41.25 \\
\hline Amburoside analog & 0.46 & 232.90 & Low & Yes & No & $8.52 \times 10^{-9}$ & 98.24 \\
\hline
\end{tabular}

\subsection{Metabolism and excretion prediction of A. cearensis phytochemicals.}

As the main precursors of drug metabolism, cytochrome P450 (CYP450) isoenzymes are oxidases of the first-pass metabolism of xenobiotics. The isoenzymes CYP450 2C19 and 2C9 are oxidases that mediate the plasma concentrations of the drugs, while the isoenzymes CYP450 2D6 and 3A4 are responsible for the O-dealkylation reactions. Present in phase II metabolism, UDP-glucuronosyltransferase, or simply UGT, is responsible for adding a glucoside group in a metabolized substance, constituting a chemical entity more susceptible to excretion [32]. The screening method of Veith et al. (2009) [49] includes drug libraries approved by the US Food and Drug Administration (FDA) in the identification of potentially inhibitory substructures of five CYP450 isoenzymes: 1A2, 2C19, 2C9, 2D6, and 3A4, corresponding to $78 \%$ of the drugs in the library. In molecular docking studies, it is possible to observe that some compounds derived from coumarin are potential inhibitors of CYP1A2, while flavonoids have structural contributions with greater promiscuity of inhibition of CYP450 [50-52].

Figure 8 shows the structural contributions of Amburana cearensis phytochemicals, where it is possible to observe that ayapin (1) was the only substance to inhibit all CYP450s in this study (1A2, 2C19, 2C9, 2D6, and 3A4) with a strong negative contribution of the 1,3- 
benzodioxole molecular fragment. It is also possible to observe positive structural contributions, as in the case of the carboxyl group fragments of the phenolic acids protocatechuic (2) and vanillic (3), and the acid analogs of coumarin, o-coumaric adic (17), and their glycosylated stereoisomers (Z) and (E) -o-coumaric acid glucoside (18 and 19), as well as the ester and hydroxyl group fragments of the 6-coumaryl-protocatecuate (4), of the amburoside A and B (5 and 6) phenolic heterosides and its esterified analog (20) and the conjugated polycyclic rings of the compounds sitogluside (12) and stigmasterol glucoside (13) and, therefore, substances with low inhibitory promiscuity of the CYP450 isoenzymes. It is interesting to note that the substance 6-hydroxy-coumarin (16) is a coumarin derivative and, therefore, has low CYP450 inhibition promiscuity, inhibiting only the 1A2 family isoenzyme, with contribution from its fragment 5,6-dihydro-2H-pyran-2-one, while the non-inhibition of the other isoenzymes is due to the positive contribution of the hydroxyl group. The flavonoids 4'-methoxy-fisetin (7), isokaempferide (8), kaempferol (9), quercetin (10), and afrormosin (11), on the other hand, have greater CYP450 inhibition promiscuity with a negative contribution of the fragment 3,4-dihydro-2H-pyran-4-one. Therefore, they are slowly metabolized substances and have a high plasma concentration, except for quercetin (10) for not inhibiting the $2 \mathrm{C}$ family isoenzymes. The metabolic stability of flavonoids with some CYP450 enzymes is due to the presence of hydroxyl substituents, a molecular fragment with a low potential to inhibit these isoenzymes (Table 4).

In addition, they are substances easily biotransformed by UGT, constituting more water-soluble compounds for renal elimination, except for the substances ayapin (1), 4'methoxy-fisetin (7), and kaempferol (9), while not inhibiting the OCT2 transporter (Organic Cation Transporter 2) (Table 4).

\subsection{Antitargets screening and biological activity by the QSAR regressions.}

The growing number of inappropriate drugs has drawn the attention of medicinal chemists in recent years. In many cases, these complexities are linked to the non-fitting of compounds into therapeutic biological targets [53-55]. The regression of the quantitative structure/activity relationship (QSAR) models of the GUSAR (General Unrestricted StructureActivity Relationships) Online tool was applied to define the inhibition constants $\left(-\log _{10} K_{\mathrm{i}}\right)$ for the various biological targets of the classes of receptors, enzymes, and transporters, according to the domain of applicability of the data set [56].

Table 4. Predicted substrates and inhibitors of CYP450 isoenzymes by the fragmental method of admetSAR 2.0 tool.

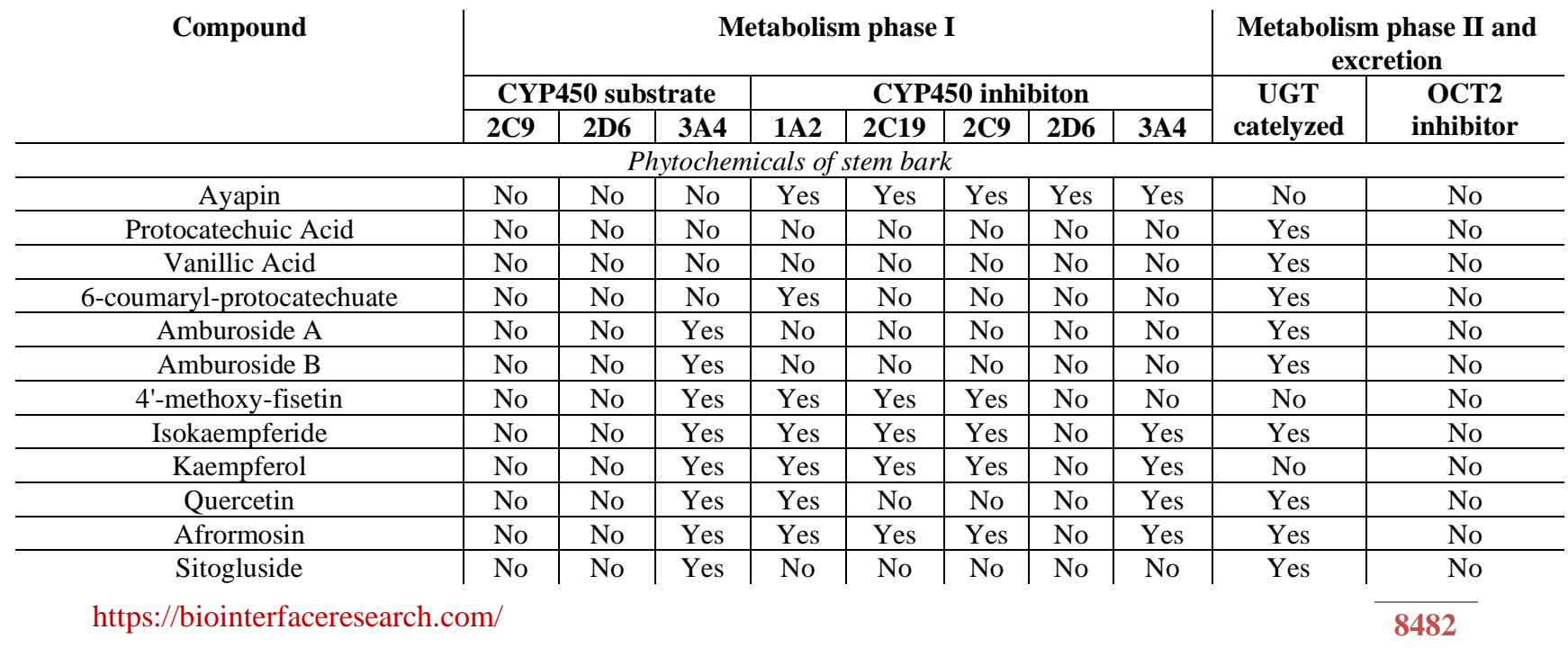




\begin{tabular}{|c|c|c|c|c|c|c|c|c|c|c|}
\hline \multirow[t]{3}{*}{ Compound } & \multicolumn{8}{|c|}{ Metabolism phase I } & \multicolumn{2}{|c|}{$\begin{array}{c}\text { Metabolism phase II and } \\
\text { excretion }\end{array}$} \\
\hline & \multicolumn{3}{|c|}{ CYP450 substrate } & \multicolumn{5}{|c|}{ CYP450 inhibiton } & \multirow{2}{*}{$\begin{array}{c}\text { UGT } \\
\text { catelyzed }\end{array}$} & \multirow{2}{*}{$\begin{array}{c}\text { OCT2 } \\
\text { inhibitor }\end{array}$} \\
\hline & $2 \mathrm{C9}$ & $2 \mathrm{D6}$ & 3A4 & 1A2 & $2 C 19$ & $2 \mathrm{C9}$ & $2 D 6$ & $\mathbf{3 A 4}$ & & \\
\hline Stigmasterol Glucoside & No & No & Yes & No & No & No & No & No & Yes & No \\
\hline Amburanin A & No & No & Yes & No & No & Yes & No & No & Yes & No \\
\hline Amburanin B & No & No & Yes & No & No & Yes & No & Yes & Yes & No \\
\hline \multicolumn{11}{|c|}{ Phytochemicals of seeds } \\
\hline 6-hydroxy-coumarin & No & No & No & Yes & No & No & No & No & Yes & No \\
\hline$O$-coumaric acid & No & No & No & No & No & No & No & No & Yes & No \\
\hline (Z)-o-coumaric acid glucoside & No & No & No & No & No & No & No & No & Yes & No \\
\hline (E)-o-coumaric acid glucoside & No & No & No & No & No & No & No & No & Yes & No \\
\hline Amburoside analog & No & No & Yes & No & No & No & No & No & Yes & No \\
\hline
\end{tabular}

In the heatmap of Figure 9A (series A) it is possible to observe that the flavonoids 4'methoxy-fisetin (7), isokaempferide (8), kaempferol (9), quercetin (10), and afrormosin (11) are potential receptor antagonists of dopamine D3 (R3DR), delta-type opioid receptor (DOR) and estrogen receptors (ER) with $-\log _{10} K_{\mathrm{i}}$ values $>5.0$. At the same time, all Amburana cearensis phytochemicals in this study may be potential inhibitors of carbonic anhydrase enzymes types 1 and 2 (HCA1 and 2), with $-\log _{10} K_{\mathrm{i}}$ values $>6.5$ (series B). Also, it is worth noting the series of inhibition of the RO5-violating compounds in this study, sitogluside (12), stigmasterol glucoside (13), amburanin A (14), and B (15), being, therefore, the compounds with the highest total number of antitargets (series $\mathrm{C}$ ), with $-\log _{10} K_{\mathrm{i}}$ values $>5.0$ for all its receptors, enzymes and transporters, except for the inhibitory activity against the enzyme monoamine oxidase A (MAOA) by the ligands sitogluside (12), stigmasterol glucoside (13). The $-\log _{10} K_{\mathrm{i}}$ values filtered by the applicability domain (AD) of the dataset are listed in Table 1 of the supplemental section.

The Prediction of Activity Spectra for Substances (PASS) method is a series of libraries that correlate in vivo animal test parameters with input compounds, generating an order of probability of activity $(\mathrm{Pa})$ and inactivity $(\mathrm{Pi})$ with biological targets and main bioactivities [33]. Thus, it is worth noting that the flavonoids 4'-methoxy-fisetin (7), isokaempferide (8), kaempferol (9), and quercetin (10) are potential inhibitors of kinases, while the acid analogs of coumarin, o-coumaric acid (17), (Z) and (E) -o-coumaric acid glucoside (18 and 19) are GPCRtype kinase inhibitors ( $G$ Protein-Coupled Receptor). At the same time, the substances protocatechuic acid (2), 6-coumaryl-protocatechuate (4), the heterosides amburoside A and B (5 and 6), the analogs sitogluside (12) and stigmasterol glucoside (13) and the derivatives of coumarin, 6-hydroxy-coumarin (16), (Z) and (E) -o-coumaric acid glucoside (18 and 19) are potent inhibitors of oxidoreductases. Therefore, the phytochemicals of A.cearensis have $\mathrm{Pa}>$ $0.70(70 \%)$ to act with the main enzymes of the glycolytic pathways (Table 5).

The anti-inflammatory and antioxidant activity models reported in the folk medicine of A. cearensis, as well as the fight against respiratory diseases [12,57] is validated in the prediction with the PASS Online tool since most substances obtained a $\mathrm{Pa}>0.50$ score for the anti-inflammatory and antioxidant activities of the server database regression models. Still, except for the phenolic acids protocatechuic (2) and vanillic (3), they are substances with a high probability of antiprotozoal activity against Leishmania $(\mathrm{Pa}>5.0)$, at the same time as the amburosides A and B (5 and 6), sitogluside (12), and the (Z) and (E) -o-coumaric acid glucoside stereoisomers (18 and 19) stand out with antiviral activity of the Influenza virus (H1N1) dataset model, with a $P a>0.70$ score (Table 5). 


\subsection{Evaluation of acute rat toxicity and toxic effects.}

The acute toxicity model in rodents is often used to detect the harmful effects of new bioactive drugs. In this work, lethal dose values (LD50) were predicted in rats for oral and subcutaneous (SC) administration routes through a self-consistent QSAR regression model based on the descriptors of quantitative electron topological atom neighborhoods (QNA) from the GUSAR Online tool, combined with the toxicity end-point models of the PASS method, performing a virtual screening to detect the compounds with lower toxicological risk [35].

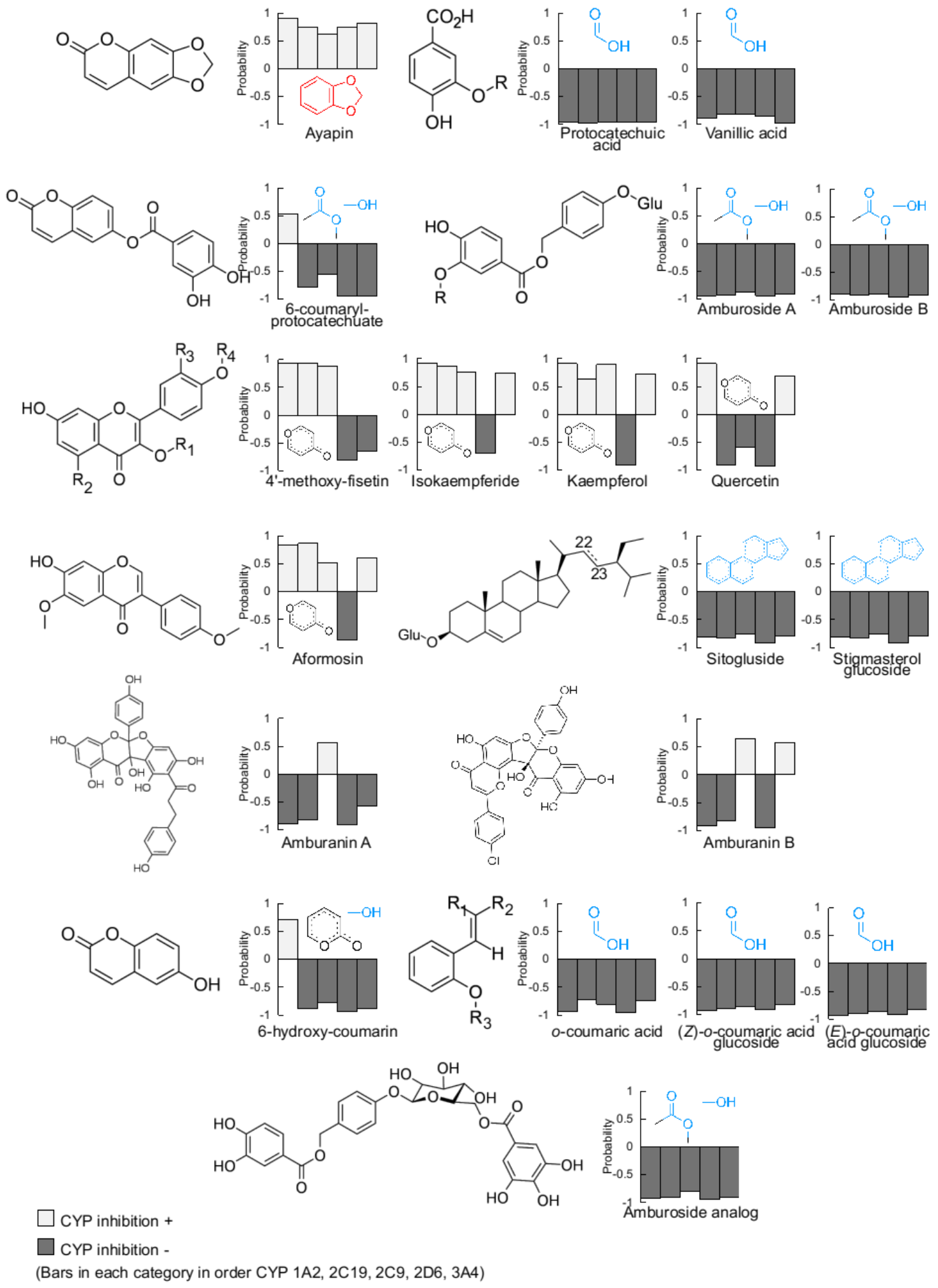

Figure 8. Structural contributions for CYP450 inhibition of phytochemical isolated from A. cearensis. 
Table 5. Prediction of inhibition of biological targets and biological activity of phytochemicals from $A$. cearensis by the PASS Online tool.

\begin{tabular}{|c|c|c|c|c|c|c|c|}
\hline \multirow[t]{2}{*}{ Compound } & \multicolumn{3}{|c|}{ Target inhibition } & \multicolumn{2}{|c|}{ Antimicrobial activity } & \multicolumn{2}{|c|}{ Biological activity } \\
\hline & Kinase & OR & 3CL $L_{\text {pro }}$ & $\begin{array}{c}\text { Antiprotozoal } \\
\text { (Leishmania) }\end{array}$ & $\begin{array}{c}\text { Antiviral } \\
\text { (Influenza) }\end{array}$ & Antiinflammatory & Antioxidant \\
\hline Ayapin & 0.33 & 0.56 & 0.34 & 0.52 & 0.39 & 0.52 & 0.42 \\
\hline Protocatechuic Acid & 0.41 & 0.75 & 0.37 & 0.37 & 0.61 & 0.54 & 0.40 \\
\hline Vanillic Acid & 0.40 & 0.67 & 0.35 & 0.39 & 0.56 & 0.50 & 0.37 \\
\hline $\begin{array}{l}\text { 6-coumaryl- } \\
\text { protocatechuate }\end{array}$ & 0.51 & 0.78 & 0.33 & 0.51 & 0.36 & 0.71 & 0.49 \\
\hline Amburoside A & $0.14^{a}$ & 0.77 & 0.21 & 0.83 & 0.71 & 0.65 & 0.64 \\
\hline Amburoside B & $0.09^{a}$ & 0.70 & - & 0.85 & 0.70 & 0.62 & 0.60 \\
\hline 4'-methoxy-fisetin & 0.93 & 0.67 & 0.22 & 0.53 & 0.29 & 0.60 & 0.70 \\
\hline Isokaempferide & 0.93 & 0.57 & 0.24 & 0.58 & 0.38 & 0.70 & 0.75 \\
\hline Kaempferol & 0.96 & 0.61 & 0.24 & 0.55 & 0.40 & 0.68 & 0.86 \\
\hline Quercetin & 0.81 & 0.61 & 0.21 & 0.57 & 0.40 & 0.69 & 0.87 \\
\hline Afrormosin & 0.67 & 0.57 & 0.22 & 0.71 & 0.27 & 0.56 & 0.59 \\
\hline Sitogluside & $0.60^{b}$ & 0.89 & - & 0.67 & 0.77 & 0.62 & 0.34 \\
\hline Stigmasterol Glucoside & $0.63^{b}$ & 0.93 & - & 0.77 & 0.69 & 0.60 & 0.38 \\
\hline Amburanin A & 0.63 & 0.00 & - & 0.52 & 0.00 & 0.44 & 0.50 \\
\hline Amburanin B & 0.90 & 0.39 & - & 0.50 & 0.26 & 0.39 & 0.57 \\
\hline \multicolumn{8}{|c|}{ Phytochemicals of seeds } \\
\hline 6-hydroxy-coumarin & 0.68 & 0.82 & 0.31 & 0.53 & 0.38 & 0.63 & 0.48 \\
\hline$O$-coumaric acid & $0.84^{b}$ & 0.60 & 0.22 & 0.53 & 0.45 & 0.68 & 0.52 \\
\hline $\begin{array}{l}\text { (Z)-o-coumaric acid } \\
\text { glucoside }\end{array}$ & $0.94^{b}$ & 0.72 & - & 0.83 & 0.71 & 0.70 & 0.70 \\
\hline $\begin{array}{l}\text { (E)-o-coumaric acid } \\
\text { glucoside }\end{array}$ & $0.94^{b}$ & 0.72 & - & 0.83 & 0.71 & 0.70 & 0.70 \\
\hline Amburoside analog & 0.85 & 0.69 & 0.21 & 0.80 & 0.67 & 0.66 & 0.70 \\
\hline
\end{tabular}

Note: OR (Oxidoreductase); $\mathrm{a}=$ Acetyl-CoA-Kinase; $\mathrm{b}=\mathrm{G}$-protein-coupled receptor kinase.

(A)

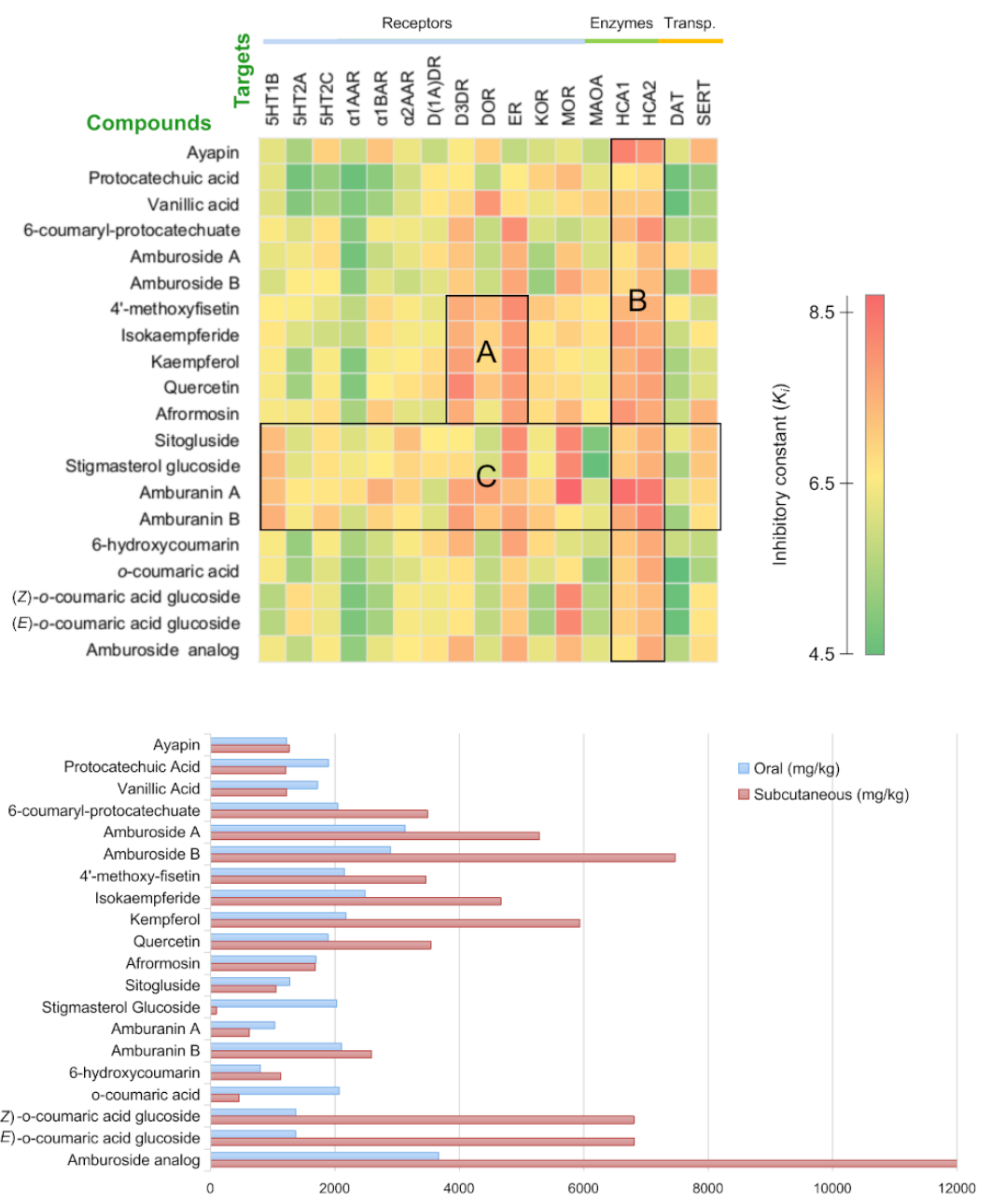

Figure 9. (A) Antitarget effects and (B) acute rodent toxicity of oral and subcutaneous administration routes by the QNA-QSAR models. 
In the graph in Figure 9B, it is possible to notice the difference between the values obtained for $\mathrm{LD}_{50}(\mathrm{mg} / \mathrm{kg})$ from oral and subcutaneous administrations of Amburana cearensis phytochemicals. Among the compounds with good oral bioavailability, it is possible to highlight the coumarin derivatives 6-coumaryl-protocatechuate (4) and o-coumaric acid (17) and the flavonoids 4'-methoxy-fisetin (7), isokaempferol (8), and kaempferol (9) as substances with $\mathrm{LD}_{50}>2000 \mathrm{mg} / \mathrm{kg}$ and, therefore, little toxic by ingestion (Class 5) [58], in addition to not presenting hepatotoxic, mutagenic or cytotoxic risk (Table 6).

The phenolic heterosides amburoside A and B (5 and 6) and its esterified analog (20), the analogs sitogluside (12) and stigmasterol glucoside (13), and the stereoisomers (Z) and (E) -o-coumaric acid glucoside (18 and 19) are compounds with bioavailability problems and have $\mathrm{Pa}>0.70$ to be toxic by residual accumulation in the gastrointestinal tract, but they have physicochemical properties that allow their subcutaneous (SC) application since $\mathrm{LD}_{50} \mathrm{SC}$ values are higher than $3000 \mathrm{mg} / \mathrm{kg}$ suggest non-toxicity by this route of administration (Table $6)$.

Table 6. Predicted $\mathrm{LD}_{50}$ to oral and subcutaneous (SC) routes and toxicological effects of phytochemicals from A. cearensis.

\begin{tabular}{|c|c|c|c|c|c|c|c|c|}
\hline \multirow[t]{2}{*}{ Compound } & \multirow[t]{2}{*}{ Oral LD 50} & \multirow[t]{2}{*}{ SC LD $\mathbf{L D}_{\mathbf{5 0}}$} & \multicolumn{6}{|c|}{ Toxic effects probability } \\
\hline & & & Intestinal & Hepatic & Carcinoma & Mutagen & Cytotoxic & Vascular \\
\hline \multicolumn{9}{|c|}{ Phytochemicals of stem bark } \\
\hline Ayapin & 1225 & 1267 & 0.35 & 0.42 & $0.86^{B}$ & 0.29 & 0.23 & 0.73 \\
\hline Protocatechuic Acid & 1897 & 1217 & 0.66 & 0.71 & 0.33 & 0.18 & 0.27 & 0.80 \\
\hline Vanillic Acid & 1725 & 1225 & 0.60 & 0.65 & 0.24 & 0.14 & 0.28 & 0.81 \\
\hline 6-coumaryl-protocatechuate & 2046 & $3492^{b}$ & 0.53 & 0.68 & 0.50 & 0.14 & 0.32 & 0.80 \\
\hline Amburoside A & 3132 & 5287 & 0.81 & 0.58 & 0.32 & 0.29 & 0.56 & 0.78 \\
\hline Amburoside B & $2901^{b}$ & 7470 & 0.77 & 0.49 & 0.23 & 0.23 & 0.56 & 0.80 \\
\hline 4'-methoxy-fisetin & 2153 & 3463 & 0.30 & 0.46 & 0.35 & 0.27 & 0.36 & 0.78 \\
\hline Isokaempferide & 2485 & 4669 & 0.34 & 0.62 & $0.53^{T}$ & 0.42 & 0.41 & 0.83 \\
\hline Kaempferol & 2183 & 5938 & 0.32 & 0.56 & $0.70^{T}$ & 0.46 & 0.40 & 0.77 \\
\hline Quercetin & 1892 & $3550^{b}$ & 0.33 & 0.58 & $0.61^{T}$ & 0.46 & 0.31 & 0.80 \\
\hline Afrormosin & 1694 & 1692 & 0.32 & 0.36 & 0.33 & 0.20 & 0.25 & 0.57 \\
\hline Sitogluside & 1279 & 1057 & 0.91 & 0.76 & 0.35 & 0.00 & 0.71 & 0.82 \\
\hline Stigmasterol Glucoside & 2033 & 95.02 & 0.94 & 0.58 & 0.46 & 0.00 & 0.70 & 0.80 \\
\hline Amburanin A & 1033 & 630.9 & 0.00 & 0.30 & 0.00 & 0.00 & 0.00 & 0.50 \\
\hline Amburanin B & 2109 & 2592 & 0.00 & 0.41 & 0.26 & 0.20 & 0.25 & 0.66 \\
\hline \multicolumn{9}{|c|}{ Phytochemicals of seeds } \\
\hline 6-hydroxy-coumarin & 805.4 & 1130 & 0.52 & 0.60 & 0.53 & 0.28 & 0.38 & 0.82 \\
\hline$o$-coumaric acid & 2071 & 463.1 & 0.48 & 0.65 & $0.40^{B}$ & 0.27 & 0.22 & 0.53 \\
\hline (Z)-o-coumaric acid glucoside & 1371 & 6810 & 0.75 & 0.58 & 0.48 & 0.33 & 0.52 & 0.53 \\
\hline (E)-o-coumaric acid glucoside & 1371 & 6810 & 0.75 & 0.58 & 0.48 & 0.33 & 0.52 & 0.53 \\
\hline Amburoside analog & 3669 & $1.2 \times 10^{4}$ & 0.74 & 0.48 & 0.34 & 0.32 & 0.54 & 0.63 \\
\hline
\end{tabular}

\section{Conclusions}

The physicochemical properties are parameters that favor ADME attributes, such as solubility, permeability, and oral absorption. The structure and activity/property relationships (SAR/SPA), as well as in silico ADME tests, indicate a high ADME viability of the coumarin 6-coumaryl-protocatechuate (4) and o-coumaric acid (17) derivatives, as well as the 4'methoxy-fisetin flavonoids (7), isokaempferide (8), kaempferol (9), quercetin (10) and afrormosin (11) while having an active pharmacological principle as an oral drug with low toxic risk, while the substances amburoside A and B (5 and 6) and its esterified analog (20), the analogs sitogluside (12) and stigmasterol glucoside (13) and the stereoisomers (Z) and (E) -o-coumaric acid glucoside (18 and 19) have physicochemical properties that guarantee their use as local action medications via the topical route. 


\section{Funding}

This research was funded by PQ/BPI-FUNCAP (Grant\#: BP4-0172-00075.01.00/20) and CNPq (Grant: 305719/2018-1).

\section{Acknowledgments}

This work was partially funded by CNPq-National Council for Science and Technological Development and CAPES - Brazilian Federal Agency for Support. We thank Ceará Foundation of Support for Scientific and Technological Development (FUNCAP) for Doctoral's degree grant (10/2018), Dean's Office of Extension from the Ceará State University (PROEX-UECE) for Initiation grants (86-87/2019). We also thank Ceará State University for the facilities to carry out this work.

\section{Conflicts of Interest}

The authors declare no conflict of interest.

\section{Supplementary material}

Table S1. Inhibitory constants (Ki) of anti-target models to the phytochemicals from Amburana cearensis by the QSAR datasets of GUSAR anti targets tool.

\section{References}

1. Halgren, T.A. Merck Molecular Force Field. I. Basis, Form, Scope, Parameterization, and Performance of MMFF94. J. Comput. Chem. 1996, 17, 490-519, https://doi.org/10.1002/(SICI)1096987X(199604)17:5/6<490::AID-JCC1>3.0.CO;2-P.

2. Koehn, F.E.; Carter, G.T. The Evolving Role of Natural Products in Drug Discovery. Nat. Rev. Drug Discov. 2005, 4, 206-220, https://doi.org/10.1038/nrd1657.

3. Baker, D.D.; Chu, M.; Oza, U.; Rajgarhia, V. The Value of Natural Products to Future Pharmaceutical Discovery. Nat. Prod. Rep. 2007, 24, 1225-1244, https://doi.org/10.1039/b602241n.

4. Atanasov, A.G.; Zotchev, S.B.; Dirsch, V.M.; Supuran, C.T. Natural Products in Drug Discovery: Advances and Opportunities. Nat. Rev. Drug Discov. 2021, 20, 200-216, https://doi.org/10.1038/s41573-020-00114-z.

5. Sandoval, M.; Okuhama, N.N.; Zhang, X.J.; Condezo, L.A.; Lao, J.; Angeles, F.M.; Musah, R.A.; Bobrowski, P.; Miller, M.J.S. Anti-inflammatory and Antioxidant Activities of Cat's Claw (Uncaria Tomentosa and Uncaria Guianensis) Are Independent of Their Alkaloid Content. Phytomedicine 2002, 9, 325-337, https://doi.org/10.1078/0944-7113-00117.

6. Gentile, D.; Patamia, V.; Scala, A.; Sciortino, M.T.; Piperno, A.; Rescifina, A. Putative Inhibitors of SARSCoV-2 Main Protease from A Library of Marine Natural Products: A Virtual Screening and Molecular Modeling Study. Mar. Drugs 2020, 18, https://doi.org/10.3390/md18040225.

7. Leal, L.K.A.M.; Matos, M.E.; Matos, F.J.A.; Ribeiro, R.A.; Ferreira, F. V.; Viana, G.S.B. Antinociceptive and Antiedematogenic Effects of the Hydroalcoholic Extract and Coumarin from Torresea Cearensis Fr. All. Phytomedicine 1997, 4, 221-227, https://doi.org/10.1016/S0944-7113(97)80071-2.

8. Leal, L.K.A.M.; Nechio, M.; Silveira, E.R.; Canuto, K.M.; Fontenele, J.B.; Ribeiro, R.A.; Viana, G.S.B. AntiInflammatory and Smooth Muscle Relaxant Activities of the Hydroalcoholic Extract and Chemical Constituents from Amburana Cearensis A. C. Smith. Phyther. Res. 2003, 17, 335-340, https://doi.org/10.1002/ptr.1139.

9. Silva, J.H.C.; Ferreira, R.S.; Pereira, E.P.; Braga-de-Souza, S.; Almeida, M.M.A.; dos Santos, C.C.; Butt, A.M.; Caiazzo, E.; Capasso, R.; Silva, V.D.A. da; Costa, S.L. Amburana Cearensis: Pharmacological and Neuroprotective Effects of Its Compounds. Molecules 2020, 25, https://doi.org/10.3390/molecules25153394.

10. Canuto, K.M.; Silveira, E.R. Constituintes Químicos Da Casca Do Caule de Amburana Cearensis A.C. Smith. Quim. Nova 2006, 29, 1241-1243, https://doi.org/10.1590/s0100-40422006000600018.

11. Leal, L.K.A.M.; Canuto, K.M.; Costa, K.C.S.; Nobre-Júnior, H.V.; Vasconcelos, S.M.; Silveira, E.R.; Ferreira, M.V.P.; Fontenele, J.B.; Andrade, G.M.; Viana, G.S.B. Effects of Amburoside a and Isokaempferide, Polyphenols from Amburana Cearensis, on Rodent Inflammatory Processes and Myeloperoxidase Activity in Human Neutrophils. Basic Clin. Pharmacol. Toxicol. 2009, 104, 198-205, https://doi.org/10.1111/j.1742-7843.2008.00329.x. 
12. Almeida, J.R.G.S.; Guimarães, A.G.; Siqueira, J.S.; Santos, M.R. V; Lima, J.T.; Nunes, X.P.; Quintans, L.J. Amburana Cearensis - Uma Revisão Química e Farmacológica. Sci. Plena 2010, 6, 1-8.

13. Canuto, K.M.; Silveira, E.R.; Bezerra, A.M.E. Estudo Fitoquímico de Espécimens Cultivados de Cumaru (Amburana Cearensis A. C. Smith). Quim. Nova 2010, 33, 662-666.

14. Oliveira, M.T.A.; Moura, G.M.M.; da Cruz, J.I.O.; Lima, R.V.C.; dos Santos, E.A.; Andrade, J.C.; Alencar, M.V.O.B.; Landim, V.P.A.; Coutinho, H.D.M.; Uchoa, A.F. Serine Protease Inhibition and ModulatoryAntibiotic Activity of the Proteic Extract and Fractions from Amburana Cearensis. Food Chem. Toxicol. 2020, 135, https://doi.org/10.1016/j.fct.2019.110946.

15. Maia-Silva, C.; Silva, C.D.; Hrncir, M.; Queiroz, R.D.; Imperatriz-Fonseca, V.L. Guia de Plantas Visitadas Por Abelhas Na Caatinga. In: Fundação Brasil Cidadão: Fortaleza. 2012; pp. 62-63.

16. Ferraz, C.A.N.; Tintino, S.R.; Teixeira, A.M.R.; Bandeira, P.N.; Santos, H.S.; Cruz, B.G.; Nogueira, C.E.S.; Moura, T.F.; Pereira, R.L.S.; Sena, D.M.; Freitas, T.S.; Rocha, J.E.; Coutinho, H.D.M. Potentiation of Antibiotic Activity by Chalcone (E)-1-(4'-Aminophenyl)-3-(Furan-2-Yl)-Prop-2-En-1-One against GramPositive and Gram-Negative MDR Strains. Microb. Pathog. 2020, 148, https://doi.org/10.1016/j.micpath.2020.104453.

17. Rocha, J.E.; de Freitas, T.S.; Xavier, J.C.; Pereira, R.L.S.; Junior, F.N.P.; Nogueira, C.E.S.; Marinho, M.M.; Bandeira, P.N.; de Oliveira, M.R.; Marinho, E.S.; Teixeira, A.M.R.; dos Santos, H.S.; Coutinho, H.D.M. Antibacterial and Antibiotic Modifying Activity, ADMET Study and Molecular Docking of Synthetic Chalcone (E)-1-(2-Hydroxyphenyl)-3-(2,4-Dimethoxy-3-Methylphenyl)Prop-2-En-1-One in Strains of Staphylococcus Aureus Carrying NorA and MepA Efflux Pumps. Biomed. Pharmacother. 2021, 140, https://doi.org/10.1016/j.biopha.2021.111768.

18. Leal, A.L.A.B.; da Silva, P.T.; da Rocha, M.N.; Marinho, E.M.; Marinho, E.S.; Marinho, M.M.; Bandeira, P.N.; Nogueira, C.E.S.; Barreto, H.M.; Teixeira, A.M.R.; dos Santos, H.S. Potentiating Activity of Norfloxacin by Synthetic Chalcones against NorA Overproducing Staphylococcus Aureus. Microb. Pathog. 2021, 155, https://doi.org/10.1016/j.micpath.2021.104894.

19. de Oliveira, V.M.; da Rocha, M.N.; Magalhães, E.P.; Mendes, F.R.S.; Marinho, M.M.; de Menezes, R.R.P.P.B.; Sampaio, T.L.; dos Santos, H.S.; Martins, A.M.C.; Marinho, E.S. Computational Approach towards the Design of Artemisinin-Thymoquinone Hybrids against Main Protease of SARS-COV-2. Futur. J. Pharm. Sci. 2021, 7, https://doi.org/10.1186/s43094-021-00334-z.

20. Alves, D.R.; Rocha, M.N.; Passos, C.C.O.; Marinho, M.M.; de Morais, S.M.; Marinho, E.S. Curcumins Potentially Active against New Coronavirus (COVID-19): A Molecular Docking Comparative Study. Antiviral Res. 2020.

21. da Rocha, M.N.; Alves, D.R.; Marinho, M.M.; de Morais, S.M.; Marinho, E.S. Virtual Screening of Citrus Flavonoid Tangeretin: A Promising Pharmacological Tool for the Treatment and Prevention of Zika Fever and COVID-19. J. Comput. Biophys. Chem. 2021, 20,283-304, https://doi.org/10.1142/s2737416521500137.

22. Ertl, P.; Rohde, B.; Selzer, P. Fast Calculation of Molecular Polar Surface Area as a Sum of Fragment-Based Contributions and Its Application to the Prediction of Drug Transport Properties. J. Med. Chem. 2000, 43, 3714-3717, https://doi.org/10.1021/jm000942e.

23. Lipinski, C.A. Lead- and Drug-like Compounds: The Rule-of-Five Revolution. Drug Discov. Today Technol. 2004, 1, 337-341, https://doi.org/10.1016/j.ddtec.2004.11.007.

24. Veber, D.F.; Johnson, S.R.; Cheng, H.; Smith, B.R.; Ward, K.W.; Kopple, K.D. Molecular Properties That Influence the Oral Bioavailability of Drug Candidates. J. Med. Chem 2002, 45, 2615-2623, https://doi.org/10.1021/jm020017n.

25. Martin, Y.C. A Bioavailability Score. J. Med. Chem. 2005, 48, 3164-3170, https://doi.org/10.1021/jm0492002.

26. Wager, T.T.; Hou, X.; Verhoest, P.R.; Villalobos, A. Central Nervous System Multiparameter Optimization Desirability: Application in Drug Discovery. ACS Chem. Neurosci. 2016, 7, 767-775, https://doi.org/10.1021/acschemneuro.6b00029.

27. Ritchie, T.J.; Ertl, P.; Lewis, R. The Graphical Representation of ADME-Related Molecule Properties for Medicinal Chemists. Drug Discov. Today 2011, 16, 65-72, https://doi.org/10.1016/j.drudis.2010.11.002.

28. Zhao, Y.H.; Abraham, M.H.; Le, J.; Hersey, A.; Luscombe, C.N.; Beck, G.; Sherborne, B.; Cooper, I. RateLimited Steps of Human Oral Absorption and QSAR Studies. Pharm. Res. 2002, 19, 1446-1457, https://doi.org/10.1023/A:1020444330011.

29. Daina, A.; Michielin, O.; Zoete, V. SwissADME: A Free Web Tool to Evaluate Pharmacokinetics , DrugLikeness and Medicinal Chemistry Friendliness of Small Molecules. Nat. Publ. Gr. 2017, 7, 1-13, https://doi.org/10.1038/srep42717.

30. Daina, A.; Zoete, V. A BOILED-Egg to Predict Gastrointestinal Absorption and Brain Penetration of Small Molecules. ChemMedChem 2016, 11, 1117-1121, https://doi.org/10.1002/cmdc.201600182.

31. Yang, H.; Lou, C.; Sun, L.; Li, J.; Cai, Y.; Wang, Z.; Li, W.; Liu, G.; Tang, Y. AdmetSAR 2.0: Web-Service for Prediction and Optimization of Chemical ADMET Properties. Bioinformatics 2019, 35, 1067-1069, https://doi.org/10.1093/bioinformatics/bty707. 
32. Zhang, H.; Bastian, J.R.; Zhao, W.; Chen, H.; Shaik, I.H.; Chaphekar, N.; Caritis, S.N.; Venkataramanan, R. Pregnancy Alters CYP- and UGT-Mediated Metabolism of Buprenorphine. Ther. Drug Monit. 2020, 42, 264270, https://doi.org/10.1097/FTD.0000000000000724.

33. Filimonov, D.A.; Lagunin, A.A.; Gloriozova, T.A.; Rudik, A.V.; Druzhilovskii, D.S.; Pogodin, P.V.; Poroikov, V.V. Prediction of the Biological Activity Spectra of Organic Compounds Using the Pass Online Web Resource. Chem. Heterocycl. Compd. 2014, 50, 444-457, https://doi.org/10.1007/s10593-014-1496-1.

34. Zakharov, A.V.; Lagunin, A.A.; Filimonov, D.A.; Poroikov, V.V. Quantitative Prediction of Antitarget Interaction Profiles for Chemical Compounds. Chem. Res. Toxicol. 2012, 25, 2378-2385, https://doi.org/10.1021/tx300247r.

35. Lagunin, A.; Zakharov, A.; Filimonov, D.; Poroikov, V. QSAR Modelling of Rat Acute Toxicity on the Basis of PASS Prediction. Mol. Inform. 2011, 30, 241-250, https://doi.org/10.1002/minf.201000151.

36. Gianti, E.; Zauhar, R.J. Structure-Activity Relationships and Drug Design. In: Remington. Elsevier, 2021; pp. 129-153, https://doi.org/10.1016/B978-0-12-820007-0.00007-6.

37. Salah, T.; Belaidi, S.; Melkemi, N.; Tchouar, N. Molecular Geometry, Electronic Properties, MPO Methods and Structure Activity/Property Relationship Studies of 1,3,4-Thiadiazole Derivatives by Theoretical Calculations. Rev. Theor. Sci. 2015, 3, 355-364, https://doi.org/10.1166/rits.2015.1040.

38. Sharma, T.; Jana, S. Investigation of Molecular Properties That Influence the Permeability and Oral Bioavailability of Major $\beta$-Boswellic Acids. Eur. J. Drug Metab. Pharmacokinet. 2020, 45, 243-255, https://doi.org/10.1007/s13318-019-00599-Z.

39. Pires, D.E.V.; Kaminskas, L.M.; Ascher, D.B. Prediction and Optimization of Pharmacokinetic and Toxicity Properties of the Ligand. In: Computational Drug Discovery and Design. Humana Press: New York, NY, 2018; pp. 271-284, https://doi.org/10.1007/978-1-4939-7756-7_14.

40. Fichert, T.; Yazdanian, M.; Proudfoot, J.R. A Structure-Permeability Study of Small Drug-like Molecules. Bioorganic Med. Chem. Lett. 2003, 13, 719-722, https://doi.org/10.1016/S0960-894X(02)01035-1.

41. Lipinski, C.A. Rule of Five in 2015 and beyond: Target and Ligand Structural Limitations, Ligand Chemistry Structure and Drug Discovery Project Decisions. Adv. Drug Deliv. Rev. 2016, 101, 34-41, https://doi.org/10.1016/j.addr.2016.04.029.

42. Ghose, A.K.; Herbertz, T.; Hudkins, R.L.; Dorsey, B.D.; Mallamo, J.P. Knowledge-Based, Central Nervous System (CNS) Lead Selection and Lead Optimization for CNS Drug Discovery. ACS Chem. Neurosci. 2012, 3, 50-68, https://doi.org/10.1021/cn200100h.

43. Melkemi, N.; Belaidi, S. Structure-Property Relationships and Quantitative Structure-Activity Relationship Modeling of Detoxication Properties of Some 1,2-Dithiole-3-Thione Derivatives. J. Comput. Theor. Nanosci. 2014, 11, 801-806, https://doi.org/10.1166/jctn.2014.3431.

44. Oliveira, R.C.; Bandeira, P.N.; Lemos, T.L.G.; dos Santos, H.S.; Scherf, J.R.; Rocha, J.E.; Pereira, R.L.S.; Freitas, T.S.; Freitas, P.R.; Pereira-Junior, F.N.; Marinho, M.M.; Marinho, E.M.; Marinho, E.S.; Nogueira, C.E.S.; Coutinho, H.D.M.; Teixeira, A.M.R. In Silico and in Vitro Evaluation of Efflux Pumps Inhibition of

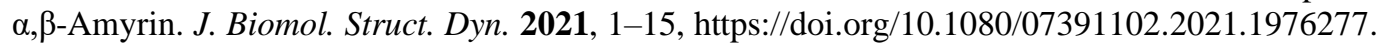

45. Atkinson, F.; Cole, S.; Green, C.; Van de Waterbeemd, H. Lipophilicity and Other Parameters Affecting Brain Penetration. Cent. Nerv. Syst. Agents. Med. Chem. 2002, 2, 229-240, https://doi.org/10.2174/1568015023358058.

46. Egan, W.J.; Merz, K.M.; Baldwin, J.J. Prediction of Drug Absorption Using Multivariate Statistics. J. Med. Chem. 2000, 43, 3867-3877, https://doi.org/10.1021/jm000292e.

47. Wildman, S.A.; Crippen, G.M. Prediction of Physicochemical Parameters by Atomic Contributions. J. Chem. Inf. Comput. Sci. 1999, 39, 868-873, https://doi.org/10.1021/ci9903071.

48. Volpe, D.A. Variability in Caco-2 and MDCK Cell-Based Intestinal Permeability Assays. J. Pharm. Sci. 2008, 97, 712-725, https://doi.org/10.1002/JPS.21010.

49. Veith, H.; Southall, N.; Huang, R.; James, T.; Fayne, D.; Artemenko, N.; Shen, M.; Inglese, J.; Austin, C.P.; Lloyd, D.G.; Auld, D.S. Comprehensive Characterization of Cytochrome P450 Isozyme Selectivity across Chemical Libraries. Nat. Biotechnol. 2009, 27, 1050-1055, https://doi.org/10.1038/nbt.1581.

50. Wang, L.; Hai, Y.; Huang, N.; Gao, X.; Liu, W.; He, X. Human Cytochrome P450 Enzyme Inhibition Profile of Three Flavonoids Isolated from: Psoralea Corylifolia: In Silico Predictions and Experimental Validation. New J. Chem. 2018, 42, 10922-10934, https://doi.org/10.1039/c7nj00884h.

51. Foroozesh, M.; Sridhar, J.; Goyal, N.; Liu, J. Coumarins and P450s, Studies Reported to-Date. Molecules 2019, 24, https://doi.org/10.3390/molecules24081620.

52. Tonholo, D.R.; Maltarollo, V.G.; Kronenberger, T.; Silva, I.R.; Azevedo, P.O.; Oliveira, R.B.; Souza, L.C.R.; Tagliati, C.A. Preclinical Toxicity of Innovative Molecules: In Vitro, in Vivo and Metabolism Prediction. Chem. Biol. Interact. 2020, 315, https://doi.org/10.1016/j.cbi.2019.108896.

53. van Laarhoven, T.; Nabuurs, S.B.; Marchiori, E. Gaussian Interaction Profile Kernels for Predicting DrugTarget Interaction. Bioinformatics 2011, 27, 3036-3043, https://doi.org/10.1093/bioinformatics/btr500.

54. Chen, X.; Liu, M.X.; Yan, G.Y. Drug-Target Interaction Prediction by Random Walk on the Heterogeneous Network. Mol. Biosyst. 2012, 8, 1970-1978, https://doi.org/10.1039/C2MB00002D. 
55. Emig, D.; Ivliev, A.; Pustovalova, O.; Lancashire, L.; Bureeva, S.; Nikolsky, Y.; Bessarabova, M. Drug Target Prediction and Repositioning Using an Integrated Network-Based Approach. PLoS One 2013, 8, https://doi.org/10.1371/journal.pone.0060618.

56. Filimonov, D.A.; Zakharov, A.V.; Lagunin, A.A.; Poroikov, V.V. QNA-Based "Star Track" QSAR Approach. SAR QSAR Environ. Res. 2009, 20, 679-709, https://doi.org/10.1080/10629360903438370.

57. Oliveira, C.R.; Cal, V.D.L.J.; Vaz, D.F.; Fialho, P.B.; Curiele, R.S.; Figueira, F.S.; da Silva, J.R.M.; Falcão, L.T.; Vieira, R.P. Known and Unknown Medicinal Plants Used in Respiratory Disorders in Brazilian Folk Medicine: A Brief Review. Brazilian J. Nat. Sci. 2021, 4, 588-605, https://doi.org/10.31415/bjns.v4i1.130.

58. Diaza, R.G.; Manganelli, S.; Esposito, A.; Roncaglioni, A.; Manganaro, A.; Benfenati, E. Comparison of in Silico Tools for Evaluating Rat Oral Acute Toxicity. SAR QSAR Environ. Res. 2015, 26, 1-27, https://doi.org/10.1080/1062936X.2014.977819. 


\section{Supplementary Data}

Table S1. Inhibitory constants $\left(K_{\mathrm{i}}\right)$ of antitarget models to the phytochemicals from Amburana cearensis by the QSAR datasets of GUSAR antitargets tool.

\begin{tabular}{|c|c|c|c|c|c|c|c|c|c|c|c|c|c|c|c|c|c|}
\hline \multirow[t]{2}{*}{ Compound name } & \multicolumn{12}{|c|}{ Receptors } & \multicolumn{3}{|c|}{ Enzymes } & \multicolumn{2}{|c|}{ Transporters } \\
\hline & 5-HT1B & 5-HT2A & 5-HT2C & Q1AAR & Q1BAR & Q2AAR & D(1A)DR & D3DR & DOR & ER & KOR & MOR & MAOA & HCA1 & HCA2 & DAT & SERT \\
\hline \multicolumn{18}{|l|}{ Phytochemicals of stem bark } \\
\hline Ayapin & $6.16^{a}$ & $5.43^{b}$ & $6.95^{b}$ & $5.75^{b}$ & $7.16^{b}$ & $6.26^{a}$ & $5.79^{b}$ & $6.45^{b}$ & $6.95^{b}$ & $5.72^{a}$ & $6.00^{b}$ & $6.23^{b}$ & $5.79^{a}$ & $8.25^{b}$ & $7.94^{b}$ & $6.11^{b}$ & $7.38^{b}$ \\
\hline Protocatechuic Acid & $6.17^{b}$ & $4.76^{b}$ & $5.22^{b}$ & $4.64^{b}$ & $5.05^{b}$ & $5.92^{b}$ & $6.58^{b}$ & $6.55^{b}$ & $5.67^{b}$ & $6.49^{a}$ & $6.94^{b}$ & $7.30^{b}$ & $6.18^{a}$ & $6.56^{b}$ & $6.75^{b}$ & $4.72^{b}$ & $5.21^{b}$ \\
\hline Vanillic Acid & $6.10^{b}$ & $4.95^{b}$ & $5.41^{b}$ & $4.91^{b}$ & $5.31^{b}$ & $6.07^{a}$ & $6.60^{b}$ & $6.83^{b}$ & $7.91^{b}$ & $6.68^{a}$ & $6.25^{b}$ & $6.77^{b}$ & $6.99^{a}$ & $7.05^{a}$ & $7.07^{a}$ & $4.60^{b}$ & $5.48^{b}$ \\
\hline 6-coumaryl-protocatechuate & $6.44^{a}$ & $6.10^{a}$ & $6.68^{b}$ & $4.99^{b}$ & $6.39^{b}$ & $6.33^{a}$ & $6.20^{b}$ & $7.42^{b}$ & $5.78^{b}$ & $8.04^{a}$ & $6.03^{b}$ & $5.77^{b}$ & $6.05^{a}$ & $7.31^{a}$ & $7.99^{a}$ & $5.57^{b}$ & $5.55^{b}$ \\
\hline Amburoside A & $6.22^{b}$ & $6.36^{b}$ & $6.78^{b}$ & $4.76^{b}$ & $5.81^{b}$ & $6.21^{b}$ & $6.72^{b}$ & $7.14^{b}$ & $5.75^{b}$ & $7.44^{a}$ & $5.44^{b}$ & $7.13^{b}$ & $6.02^{a}$ & $6.67^{a}$ & $7.29^{a}$ & $6.77^{b}$ & $6.27^{b}$ \\
\hline Amburoside B & $6.01^{b}$ & $6.49^{b}$ & $6.52^{a}$ & $5.03^{b}$ & $6.16^{b}$ & $5.84^{a}$ & $6.13^{b}$ & $7.03^{b}$ & $5.86^{b}$ & $7.65^{a}$ & $5.22^{b}$ & $7.64^{b}$ & $7.10^{a}$ & $6.81^{a}$ & $7.29^{a}$ & $5.34^{a}$ & $7.63^{b}$ \\
\hline 4'-methoxy-fisetin & $6.50^{a}$ & $6.46^{a}$ & $6.23^{a}$ & $5.69^{a}$ & $6.81^{b}$ & $6.44^{a}$ & $6.23^{a}$ & $7.56^{b}$ & $7.27^{b}$ & $8.09^{a}$ & $7.07^{b}$ & $6.78^{a}$ & $6.59^{b}$ & $7.40^{a}$ & $7.46^{a}$ & $6.57^{a}$ & $5.94^{b}$ \\
\hline Isokaempferide & $6.59^{a}$ & $6.06^{a}$ & $5.92^{a}$ & $5.69^{b}$ & $6.72^{b}$ & $6.38^{a}$ & $6.37^{a}$ & $7.49^{b}$ & $6.92^{b}$ & $7.82^{a}$ & $6.64^{b}$ & $6.97^{a}$ & $6.70^{b}$ & $7.73^{a}$ & $7.55^{a}$ & $\mathbf{5 . 8 5}^{a}$ & $6.59^{b}$ \\
\hline Kaempferol & $6.45^{a}$ & $5.30^{b}$ & $6.43^{b}$ & $4.92^{b}$ & $6.43^{b}$ & $6.53^{a}$ & $6.78^{a}$ & $7.76^{b}$ & $6.76^{b}$ & $7.96^{a}$ & $6.80^{b}$ & $6.57^{b}$ & $6.38^{a}$ & $7.44^{b}$ & $7.76^{b}$ & $5.42^{b}$ & $6.03^{b}$ \\
\hline Quercetin & $6.40^{a}$ & $5.32^{b}$ & $6.44^{b}$ & $4.94^{b}$ & $6.51^{b}$ & $6.68^{a}$ & $6.90^{a}$ & $8.18^{b}$ & $7.15^{b}$ & $7.85^{a}$ & $6.81^{b}$ & $6.76^{b}$ & $6.37^{a}$ & $7.51^{b}$ & $7.74^{b}$ & $5.47^{b}$ & $6.08^{b}$ \\
\hline Afrormosin & $6.41^{a}$ & $6.34^{a}$ & $6.74^{a}$ & $5.43^{a}$ & $7.05^{a}$ & $6.15^{a}$ & $6.10^{a}$ & $7.55^{b}$ & $6.32^{b}$ & $7.76^{a}$ & $6.72^{b}$ & $7.37^{a}$ & $6.57^{a}$ & $7.91^{a}$ & $7.59^{a}$ & $5.84^{a}$ & $7.43^{b}$ \\
\hline Sitogluside & $7.28^{b}$ & $6.05^{b}$ & $6.69^{b}$ & $6.09^{b}$ & $6.41^{b}$ & $7.22^{b}$ & $6.50^{b}$ & $6.53^{b}$ & $5.86^{a}$ & $8.10^{a}$ & $6.34^{b}$ & $8.17^{b}$ & $4.90^{a}$ & $6.96^{a}$ & $7.47^{a}$ & $6.20^{b}$ & $7.17^{b}$ \\
\hline Stigmasterol Glucoside & $7.35^{b}$ & $6.15^{b}$ & $6.68^{b}$ & $6.34^{b}$ & $6.50^{b}$ & $6.87^{b}$ & $6.71^{b}$ & $6.76^{b}$ & $6.00^{a}$ & $8.01^{a}$ & $6.43^{b}$ & $8.15^{b}$ & $4.57^{a}$ & $7.06^{a}$ & $7.47^{a}$ & $5.43^{b}$ & $7.12^{b}$ \\
\hline Amburanin A & $7.23^{a}$ & $6.57^{b}$ & $6.61^{a}$ & $6.73^{a}$ & $7.49^{b}$ & $6.94^{a}$ & $5.95^{b}$ & $7.66^{b}$ & $7.67^{b}$ & $7.27^{a}$ & $6.88^{b}$ & $8.67^{b}$ & $6.04^{a}$ & $8.56^{a}$ & $8.39^{a}$ & $6.07^{b}$ & $6.82^{b}$ \\
\hline Amburanin B & $7.48^{b}$ & $6.39^{b}$ & $7.09^{b}$ & $5.95^{b}$ & $6.91^{b}$ & $6.61^{a}$ & $6.11^{b}$ & $7.78^{b}$ & $7.11^{b}$ & $7.65^{a}$ & $7.10^{b}$ & $6.59^{a}$ & $6.23^{a}$ & $7.61^{b}$ & $8.18^{b}$ & $5.32^{b}$ & $6.67^{b}$ \\
\hline \multicolumn{18}{|l|}{ phytochemicals of seeds } \\
\hline 6-hydroxycoumarin & $6.42^{a}$ & $5.20^{b}$ & $6.43^{b}$ & $5.44^{b}$ & $5.92^{b}$ & $6.42^{b}$ & $6.83^{b}$ & $7.41^{b}$ & $5.70^{b}$ & $7.71^{a}$ & $6.80^{b}$ & $6.11^{b}$ & $5.96^{a}$ & $7.11^{a}$ & $7.58^{b}$ & $5.85^{b}$ & $5.73^{b}$ \\
\hline$o$-coumaric acid & $6.40^{a}$ & $5.31^{b}$ & $6.11^{b}$ & $5.07^{b}$ & $5.78^{b}$ & $6.08^{b}$ & $6.41^{b}$ & $6.69^{b}$ & $5.72^{b}$ & $6.95^{a}$ & $6.14^{a}$ & $6.64^{b}$ & $5.22^{a}$ & $6.95^{a}$ & $7.63^{a}$ & $4.51^{b}$ & $5.46^{b}$ \\
\hline (Z)-o-coumaric acid glucoside & $5.59^{a}$ & $6.76^{b}$ & $6.25^{b}$ & $4.84^{b}$ & $5.38^{b}$ & $6.40^{b}$ & $6.33^{b}$ & $6.61^{b}$ & $5.71^{b}$ & $7.08^{a}$ & $5.36^{b}$ & $8.14^{b}$ & $5.58^{a}$ & $6.96^{a}$ & $7.29^{a}$ & $4.63^{b}$ & $6.61^{b}$ \\
\hline (E)-o-coumaric acid glucoside & $5.59^{a}$ & $6.76^{b}$ & $6.25^{b}$ & $4.84^{b}$ & $5.38^{b}$ & $6.40^{b}$ & $6.33^{b}$ & $6.61^{b}$ & $5.71^{b}$ & $7.08^{a}$ & $5.36^{b}$ & $8.14^{b}$ & $5.58^{a}$ & $6.96^{a}$ & $7.29^{a}$ & $4.63^{b}$ & $6.61^{b}$ \\
\hline Amburanyl gallate & $6.36^{b}$ & $5.72^{b}$ & $6.44^{b}$ & $5.13^{b}$ & $6.23^{b}$ & $6.52^{b}$ & $6.64^{b}$ & $7.45^{b}$ & $6.05^{b}$ & $7.55^{a}$ & $6.21^{b}$ & $7.34^{b}$ & $6.15^{a}$ & $6.63^{a}$ & $7.58^{a}$ & $5.59^{b}$ & $6.75^{b}$ \\
\hline
\end{tabular}

Note: $a=$ in $\mathrm{AD}, b=$ out of $\mathrm{AD}$ 